\title{
Economic implications of climate change for infrastructure planning in transboundary water systems: An example from the Blue Nile
}

\author{
Marc Jeuland ${ }^{1}$ \\ Received 14 April 2010; revised 22 September 2010; accepted 30 September 2010; published 24 November 2010. \\ [1] This research develops a hydroeconomic modeling framework for integrating \\ climate change impacts into the problem of planning water resources infrastructure \\ development. It then illustrates use of that framework in evaluation of two alternative \\ sizes of a potential hydropower project along the Blue Nile in Ethiopia. Storing water in \\ a Blue Nile reservoir provides an interesting case for testing this integrated approach \\ because such a project would induce a number of physical and economic changes, both \\ transboundary and climate-dependent. The proposed framework makes two \\ contributions to the existing literature on water resources project appraisal. First, it \\ demonstrates how routinely used hydrological modeling techniques can be \\ supplemented with Monte Carlo simulation to include economic uncertainties inherent \\ in the planning problem, in addition to its more commonly considered physical \\ dimensions. Second, it demonstrates how analysts can include a number of linkages \\ between climate change, hydrology, and economic production in conventional planning \\ models to develop better understanding of the complexities and important uncertainties \\ associated with future conditions. While the framework described here has not been \\ used in a full analysis of alternative development projects in the Blue Nile, the general \\ approach could be combined with a variety of decision-analytic tools to evaluate \\ design and management alternatives in water resources systems.
}

Citation: Jeuland, M. (2010), Economic implications of climate change for infrastructure planning in transboundary water systems: An example from the Blue Nile, Water Resour. Res., 46, W11556, doi:10.1029/2010WR009428.

\section{Introduction}

[2] According to the Intergovernmental Panel on Climate Change, climate change is likely to have a complex set of impacts on water resources throughout the world [Intergovernmental Panel on Climate Change (IPCC), 2007b]. Warming attributable to rising atmospheric concentrations of greenhouse gases will affect ocean and surface temperatures, precipitation patterns, evapotranspiration rates and the demand for water in agriculture, the frequency and intensity of storms, the timing and magnitude of runoff, and sea level in coastal communities [Frederick and Major, 1997; IPCC, 2007a]. There has been extensive research and modeling aimed at assessing the magnitude of such impacts under different emissions scenarios in the global context and in specific regions [Arnell, 2004; Leavesley, 1999; Milly et al., 2005; Vicuna and Dracup, 2007]. Still, there is considerable debate and uncertainty about regional impacts. To date, little practical research and guidance exists on how the range of possible effects of global warming should be integrated into planning new capital-intensive

\footnotetext{
${ }^{1}$ Sanford School of Public Policy, Duke University, Durham, North Carolina, USA.
}

Copyright 2010 by the American Geophysical Union. 0043-1397/10/2010WR009428 investments in water resources, as well as renewal of old infrastructures.

[3] This research develops a hydroeconomic modeling framework for integrating climate change into the problem of water resources infrastructure decision making. In theory, there are a very large number of potential linkages and feedbacks between climate change and water resources systems (Figure 1a), and tractability precludes inclusion of all of them at one time in a given analysis. There is, however, a need for an investment planning framework that could accommodate the diverse interrelationships between climate and water. The framework proposed in this paper allows for consideration of a reduced set of physical and economic impacts of climate change (Figure 1b). As such, they can better be considered simultaneously. To achieve this, the framework first includes explicit functional linkages between climatic factors (such as temperature and precipitation), specified based on General Circulation Model or other relevant future projections, and many of the hydrological model components that these factors influence. Such components include relationships with runoff, net evaporation from reservoirs and lakes, water demands, flood and drought risks in the system, and streamflow routing equations. The proposed framework thus allows comparison of system outputs in physical terms under historical and changed conditions.

[4] The framework also allows analysis of economic uncertainties and relative changes in the real value and 


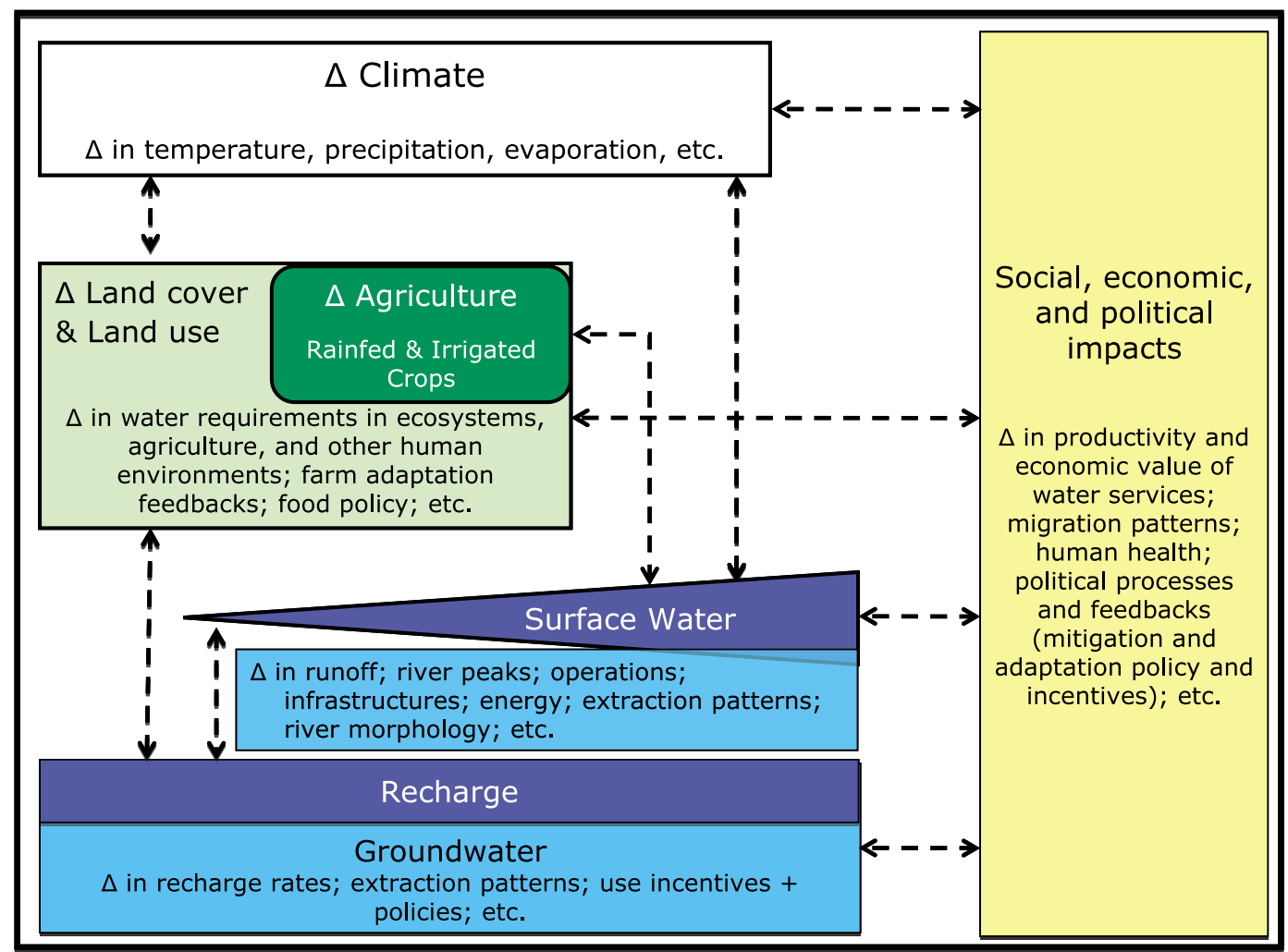

\section{A}

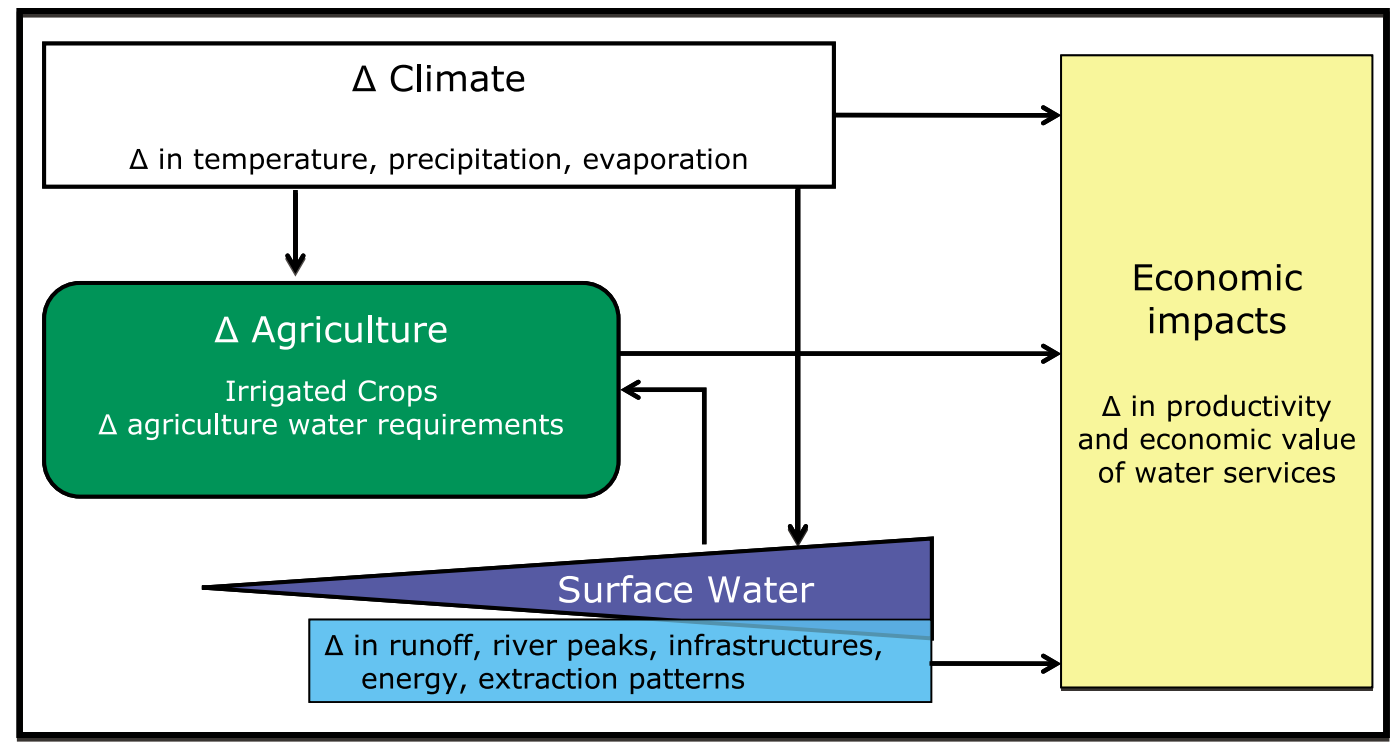

B

Figure 1. A conceptual diagram showing (a) key linkages and feedbacks between climate change, water resources, and human systems and (b) the relationships specifically considered in the application described in this research.

productivity of the goods and services generated by hydrological systems. The economic value of physical outputs of such systems is likely to be influenced by changing climate, a fact that has not been widely acknowledged in the water resources planning literature. Large-scale changes in temperature and precipitation, for instance, are likely to influence the demand for water and hydropower, via at least two types of changes. First, the economics of the production processes using these inputs may be altered, if farmers increase or decrease their use of irrigation based on changes in temperature and rainfall. In supply constrained systems, this could lead to increases, or decreases, in the economic value of water. Also, energy suppliers and society may favor hydroelectric power generation to conventional fossil sources if carbon offsets gain value or if conventional energy sources become relatively more costly. 
[5] Second, consumption patterns of resources will be altered. For example, warmer temperatures may increase the demand for cooling energy while decreasing heating requirements. Sea level rise may increase the demand for environmental releases in river basins threatened with salt water intrusion. Indeed, relative changes in the value derived from resources affected by climate change play an important role in determining its economic consequences [Sterner and Persson, 2008]. While it is very difficult to predict changes in relative economic values over the course of a long project lifespan, it is important to acknowledge that these effects could compensate for or exacerbate the physical effects of climate change. They could also alter the trajectory of efficient, or even socially beneficial, policies and investments in infrastructure.

[6] Given the high level of uncertainty associated with these types of physical and economic changes, it would seem that a new approach for integrating the economic valuation problem with standard water resources project appraisal methods would be useful. Current water resources planning methods were largely developed during the first half of the twentieth century, and extended through the contributions of the Harvard Water Program and many others [see, e.g., Maass et al., 1962; Hufschmidt and Fiering, 1966]. Such analyses usually rely on some form of economic optimization to allocate water to its highest value uses or to maximize net benefits resulting from investment in new infrastructures [Harou et al., 2009], but they are rarely used outside of academia (except perhaps in specialized operational applications). Planners who do use optimization often complement it with simulation methods, in order to address hydrological risks and uncertainties. However, even they tend to treat economic factors (or cost and benefit curves) as fixed parameters (or functions) within the valuation equations that are used to calculate the net benefits of new projects.

[7] This paper is not the first to suggest some need for rethinking these planning methods. Critiques of standard planning approaches have largely been motivated by a heightened concern over climate change, although changing conditions (defined broadly) have long presented problems for water resources specialists [Lettenmaier, 2008]. In effect, it is no coincidence that there is a large body of research demonstrating new modeling approaches for integrating climate change aspects into hydrological planning applications [Frederick et al., 1997; Lettenmaier et al., 1999; Stakhiv, 1998]. To date, however, this research has generally been limited to the physical aspects of water resources systems, and provides only limited insights into the economic implications of changed conditions. Analyses limited to physical impacts may miss critical economic feedbacks, leading to erroneous conclusions about project net benefits. It may seem counterintuitive, but a hydropower dam could actually generate greater economic benefits if river flows are reduced under climate change. For example, increases in the real value of power plus the value of carbon offsets might outweigh losses associated with reduced power production. Similarly, the value of an irrigation dam may decrease when river flows increase, if the value of storage decreases due to reduced water scarcity.

[8] The paper is organized as follows. Section 2 describes in basic terms the elements of the framework that is typically used in systems planning applications, explains some of its key assumptions, and offers a proposal for extending that assessment framework to better consider uncertainty over future conditions. Section 3 specifies how this modified approach is made operational, and discusses the models used in this paper's Nile Basin application. Section 4 describes the project alternatives and analyses used to illustrate the modified framework. Section 5 presents results pertaining to the influence of different components of climate change and project uncertainties on the economic outcomes of the example reservoir project. A discussion of these results follows in section 6 , and section 7 concludes.

\section{Comparing Current Water Resources Planning Models With the Proposed Framework}

\subsection{Standard Water Resources Planning Model}

[9] In its simplest form, the typical water resources planning problem taught to water resources professionals in graduate level courses is set up as a deterministic optimization problem that treats hydrologic or economic parameters and functions as fixed and known quantities [Loucks et al., 1981, 2005; Maass et al., 1962; ReVelle and McGarity, 1997] (there are of course a very large number of different variations of the basic model presented here, which is used only for illustrative purposes). Though the form of the objective function varies, the most appropriate economic criterion is to maximize the net present value (NPV) obtained from the universe of potential infrastructure(s) options. Other common formulations are to minimize investment costs subject to constraints on water supply reliability or power generation capacity, or to maximize benefits subject to cost or other constraints [ReVelle and McGarity, 1997]. A variety of studies using different objective functions can be found in the literature; a detailed summary is not presented here. Many of today's water resources modeling packages can be parameterized to allow economic optimization, given assumptions or data on the demand for hydropower, irrigation and other water supply, and other water system outputs.

[10] The constraint structure of deterministic economic optimization models used in water resources is largely provided by system continuity equations, calibrated using observed historical flows. In the simplest applications of these models, analysts use optimization techniques to explore the economic value of system impacts that would have resulted if different (and new) flow regulating infrastructures or consumptive water withdrawals were present in it, and/or if its existing allocations or operating strategies were altered. Objectives other than maximizing NPV can be incorporated with additional constraints.

[11] As planning tools, economic optimization models are particularly useful for screening project alternatives, i.e., for narrowing the choice set. They allow a detailed focus on specific regions or types of infrastructures that are likely to generate the greatest net benefits. For example, this paper considers the economic performance of a potential hydropower dam in the Eastern Nile, a region for which optimization tools have been used to motivate additional study of possibilities for hydropower in the Ethiopian Blue Nile [Whittington et al., 2005; Wu and Whittington, 2006].

[12] Nonetheless, water resources planning textbooks acknowledge that deterministic economic optimization at best constitutes a partial analysis. Its key shortcoming is the assumption of perfect foresight; water resources managers are allowed to know river flows with certainty, and to operate 


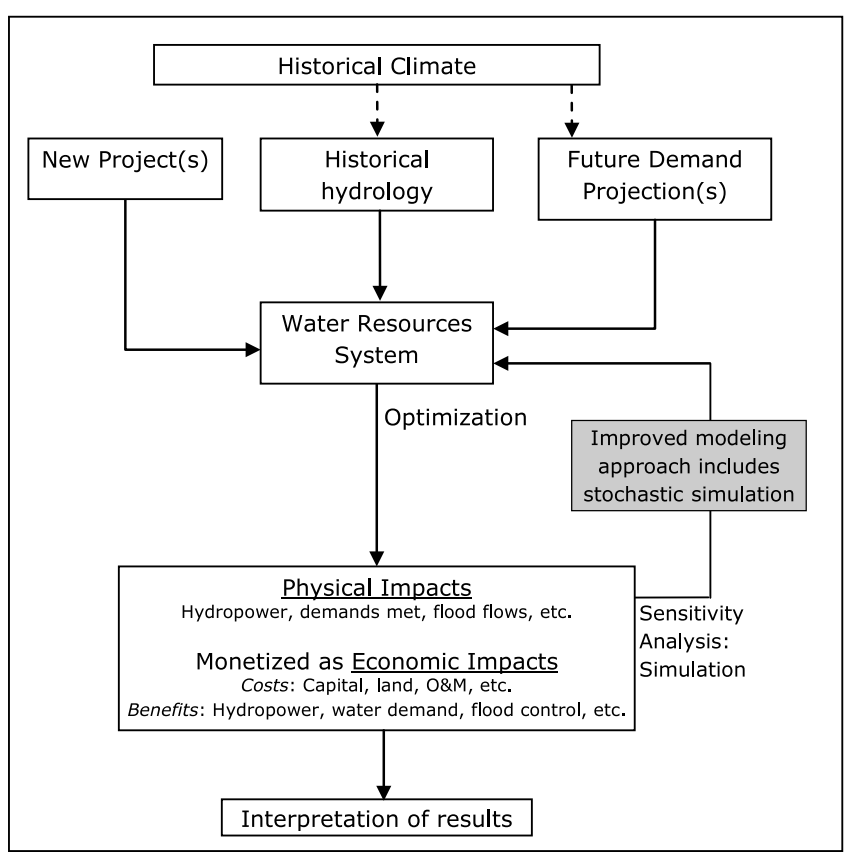

Figure 2. The standard framework for economic appraisal of water resources investments. In this diagram, the shaded box represents a stochastic simulation procedure that is not always used by analysts; dashed arrows represent assumptions of maintained climate conditions behind this approach.

the system efficiently based on that knowledge, allocating water to its known highest value uses [Harou et al., 2009]. More complete project planning (Figure 2) usually relies on use of operating rules developed based on the results of optimization to conduct repeated simulations that test the sensitivity of results to important uncertainties: model assumptions, natural variability in river flows, future water demands, or infrastructure design parameters. At best, the planner will supplement simulations based on the historical flows with ones that use stochastic flows, in order to better understand the risks that are associated with the different system designs and/ or operating rules [Harou et al., 2009; Loucks et al., 1981]. Stochastic linear programming or dynamic programming can also help guide design and refinement of operating rules, though the objective function of these models is usually limited to physical objectives [Yeh, 1985].

[13] When conducting economic analysis of new investments or management strategies, modelers tend to analyze "worst" and "best" case scenarios that correspond to pessimistic and optimistic assumptions about the future; these are considered to generate reasonable upper and lower bound indicators of the performance of alternative investments. Probabilities are sometimes assigned to these future scenarios, such that analysts can compute and consider the expected NPV of different project options. These planning studies generally assume that historical climate conditions provide sufficient information for reliably predicting future system behavior.

\subsection{Challenges to Use of the Standard Planning Model}

[14] In the past, it has been argued that this planning model is very infrequently used in real-world systems design [Rogers and Fiering, 1986] and that reservoir operating rules are only rarely developed based on results obtained from systems analysis techniques [Yeh, 1985]; these points are reiterated in a recent review of hydroeconomic models [Harou et al., 2009]. More precisely, it is clear that hydrological routing models and other types of water resources modeling tools are widely used by engineers and planners around the world, but that systems optimization applications, particularly economic optimization, remain rare outside academia, despite the emergence of the integrated water resource management paradigm [Bouwer, 2002]. This is somewhat surprising considering the number of such applications in the academic water resources literature.

[15] Scholars offer a number of explanations for why such models have not made greater inroads among practitioners. Rogers and Fiering [1986] emphasize institutional resistance and contextual factors. In the U.S., even as economic analysis of large public investment projects was first initiated in the field of water resources [Hanemann, 1992; Inter-Agency River Basin Committee, 1950], systems planning techniques developed too late to influence project selection. Infrastructures were built piecemeal and integrated river basin plans were rare. Furthermore, the economic studies ostensibly used to guide implementation decisions only played a marginal role in the ultimate choices that were made [Eckstein, 1958; Krutilla and Eckstein, 1958]. In developing countries, reasons posited for resistance to systems optimization models include insufficiencies of high-quality data, a paucity of tools that are complete enough to test the robustness of "optimal" solutions, and a lack of stakeholder involvement in model development.

[16] Rogers and Fiering [1986] and Harou et al. [2009] discuss other technical and interpretation problems related to optimization models. In the context of this paper, four interrelated issues stand out: (1) the challenge of how to deal with general planning uncertainties, some of which are very large; (2) the lack of sensitivity of many systems to wide variations in design alternatives; (3) the existence of multiple near optimal alternatives; and (4) an inability to easily represent social, political and/or environmental objectives and risk aversion in the mathematical statements of optimization models. These issues interact to create a situation in which assumptions about parameter values or the appropriate formulation of constraints might plausibly lead to different optimal infrastructure bundles, although formal tests of this proposition are rare. It seems at least possible that multiple system designs could be justified in many cases; economic optimization models may then have little to say about the relative strengths of different options.

\subsection{Toward an Integrated Simulation-Based Approach: Understanding General Uncertainties of the Systems Planning Model}

[17] This section highlights many of the uncertainties which create challenges for planners who would use typical models for economic appraisal of projects in water resources. First, detailed time series data used to calibrate (and simulate) the system continuity equations, especially net evaporation from reservoirs, seepage, and water demands, is rarely available. Second, there may be a lack of confidence in the historical record of inflows or concerns over the long-term 


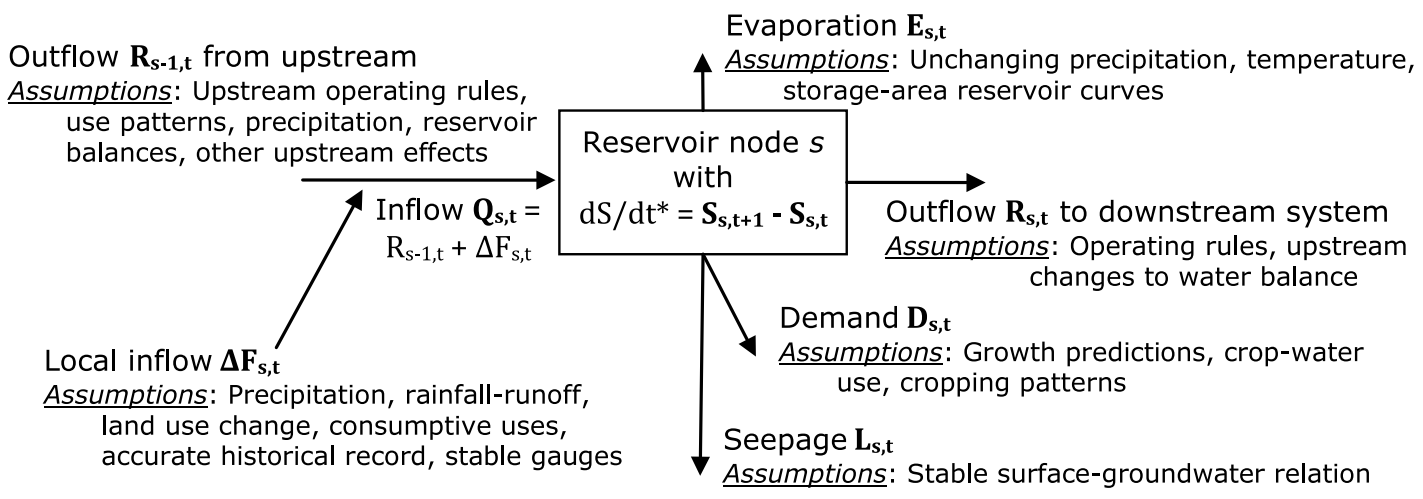

* Assumptions: Silt deposition in reservoirs, changes to reservoir water balance

Figure 3. Illustrative representation of mass balance on nodes modeled in a water resources system, with description of typical assumptions.

stability of model calibrations developed using the instrumental record; a notable example is the Nile Basin discussed later in this paper [see Hassan, 1981; Shahin, 1985; Davies and Walsh, 1997; Nicholson, 2001; Nicholson and Yin, 2001; Marchant and Hooghiemstra, 2004]. Third, it is difficult to consider important economic uncertainties using the standard planning model. This is a major problem given that the NPV of capital-intensive water resources projects is known to be highly sensitive to economic parameters such as the discount rate, infrastructure costs, the value of irrigation water, etc. Fourth, some relevant costs and benefits may be difficult to monetize and omitted from the objective function, making it difficult to interpret economic outcomes (and creating a temptation to appeal to "intangible" or secondary benefits to justify projects).

[18] There is also a whole set of uncertainties related to future projections of system behavior, over the time horizon of interest to the planner (see Figure 3 for a conceptual diagram of how these enter into water resources system continuity equations). Projection of future consumptive water demands is difficult, especially when considering long-lived infrastructures that have the potential to foster large-scale, regional economic changes. There could also be systematic changes in the quantity, variability, and timing of runoff due to climate or land use changes, which remain uncertain and hard to represent despite advances in modeling (see Wood et al. [1997] or IPCC [2007a] for further discussion). Climatic perturbations are likely to interact with other parts of the system, altering physical properties such as net evaporation from reservoirs, demands for irrigation water and reservoir storage via changes in siltation rates. Plus, existing management regimes and usage patterns are endogenous and may themselves change in response to longterm perturbations in climate or settlement patterns, with system-wide consequences.

[19] These various issues may explain why ex post reviews of large water projects have often disagreed with the predictions of ex ante analyses. For example, the World Commission on Dams [2000] found that hydropower production from many large dams was often much lower than planners originally expected, and that assumptions about infrastructure costs were usually too low, both of which often led to overestimates of net benefits.

\subsection{A Proposed Integrated Hydroeconomic Simulation Model for Project Appraisal}

[20] Given these challenges, this paper proposes to extend the standard project evaluation framework, using the power of simulation methods to allow tests of the performance of different system configurations in various plausible, different states of the world. Such a simulation framework could not only be used to test the effect of natural variability and climate change on the physical behavior of water resources systems, as is routine in the field of water resources, but also the effects of those changes on the economic value of the physical outputs those systems generate. Furthermore, it could help to identify which assumptions about system behavior have the most influence on the performance of planned investments or policy changes. Greater knowledge of such sensitivities should help inform the selection of more robust projects and designs.

[21] An operational representation of the proposed framework is shown in Figure 4. As shown, it contains eight steps and three sets of linked models, for streamflow generation, hydrological simulation, and finally calculation of net benefits. Steps 1 through 5 occur within the hydrological portion of the framework; steps 6 through 8 make up its economic portion.

[22] 1. First, define $k$ future scenarios $[1, \ldots, K]$ and $p+1$ infrastructure or management experiments $[0, \ldots, P]$, where $p=0$ is the "no project" baseline configuration. Second, choose the first scenario $(k=1)$ and the "no project" configuration $(p=0)$.

[23] 2. Specify climatic and economic parameter values and linkages for scenario $k$ (e.g., theoretical and/or empirical relationships governing net evaporation from reservoirs, water demands, changes in routing, economic value of system outputs, etc.).

[24] 3. Use a streamflow generation model to create $n$ sequences of synthetic inflows $[1, \ldots, N]$ corresponding to the runoff characteristics for the chosen scenario $k$, each of which is at least as long as the potential lifespan for the project(s) being assessed.

[25] 4. Use a hydrological model to conduct simulation with each of the inflow sequences to generate $N$ series of physical output measures for the system performance over 


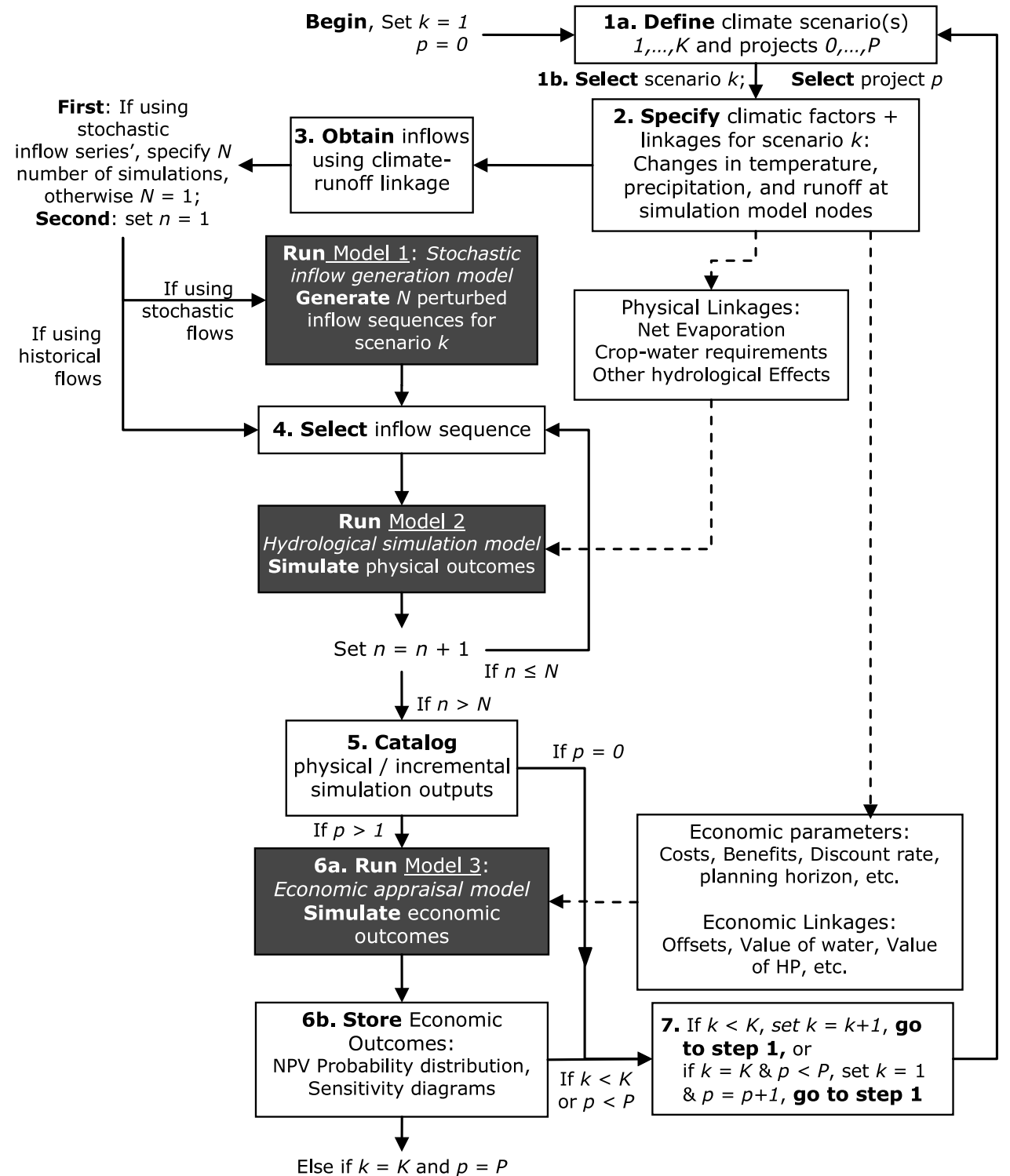

8. Stop and process results

Figure 4. Flowchart showing the connections between the models of the proposed framework. Solid arrows show the eight steps of the operational framework, and dashed lines represent functional linkages among model components.

the relevant time horizon (or alternatively, use only a single historical series for analysis).

[26] 5. Store the physical outputs from the system; then, if $p=0$, skip to step 7, otherwise calculate incremental changes in the outputs due to new project $p$ (where $p=1$, $\ldots, P)$ relative to the "no project" $(p=0)$ baseline.

[27] 6. Calculate the net present value (NPV) of project $p$ in climate scenario $k$ by using Monte Carlo procedures to make random draws from the $N$ sequences of incremental measures from step 5 and the specified distributions of uncertain parameters in the economic valuation equations.

[28] 7. If $k<K$ and $p<P$, choose the next future scenario $k+1$, or if $k=\mathrm{K}$ and $p<\mathrm{P}$, set $k=1$ and choose the next project $p+1$ and repeat steps 1 through 6 (otherwise go to step 8).

[29] 8. When all projects $P$ have been assessed in all scenarios $K$, analyze results and compare the performance of alternative plans across multiple scenarios with the aid of decision rules (such as minimax criteria for project risks or rules that put weight on projects that balance downside risks and upside benefits).

\section{Using the Hydroeconomic Simulation Framework: Nile Basin Example}

[30] This section describes in more detail how the general framework described above is used to evaluate the effects of a set of climate change linkages on the economic appraisal of a potential infrastructure project in the Nile Basin.

\subsection{Component Models for the Application}

[31] Basic information on the three models used for the Nile modeling application explored in this paper is presented in this section. Additional details on the calibration 


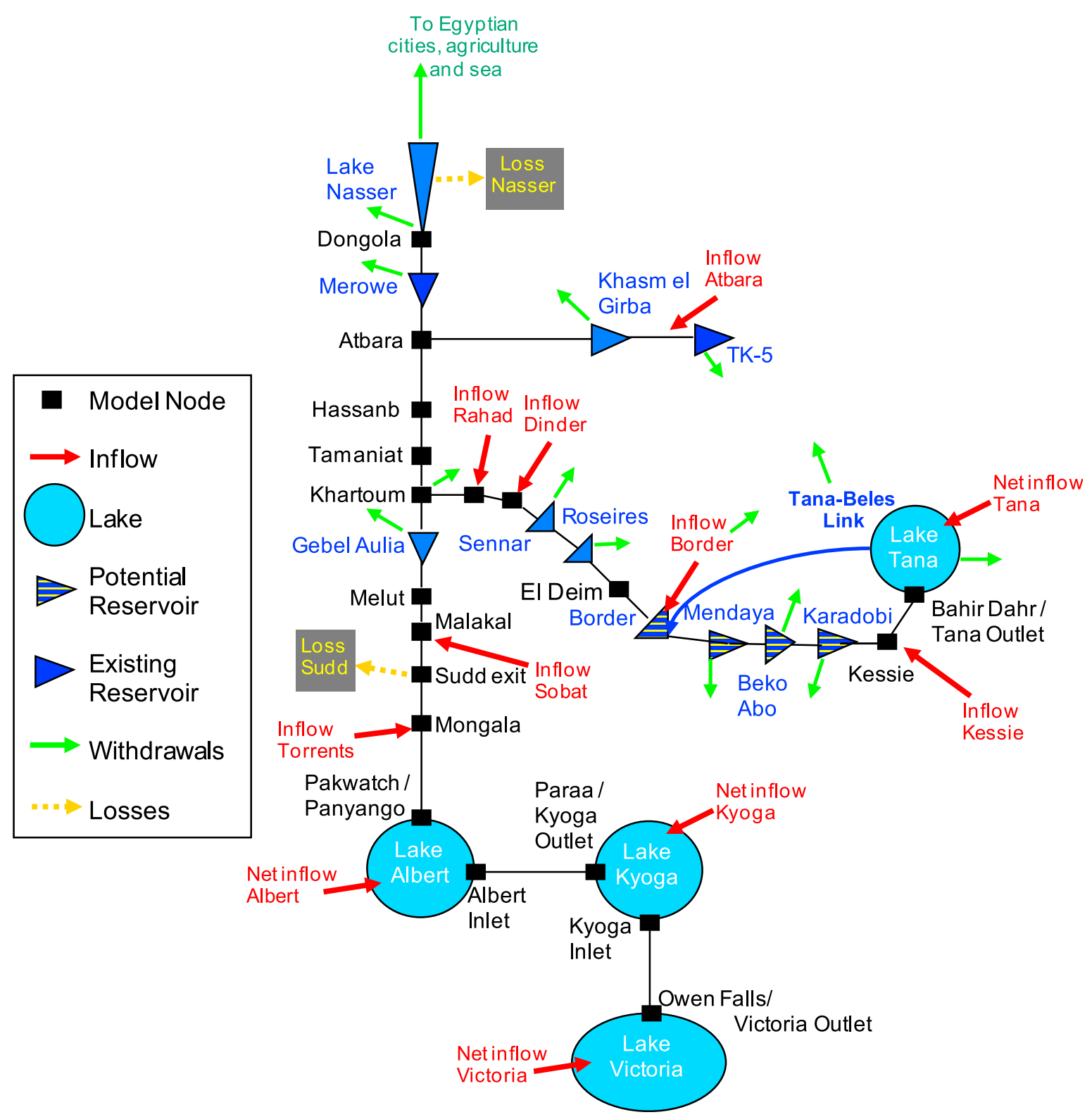

Figure 5. Nile model schematic. Inflows for the 11 nodes are generated using the stochastic simulator, which preserves cross-node correlations.

and parameterization of these models are available in the auxiliary material. ${ }^{1}$

\subsubsection{A Stochastic Streamflow Generator}

[32] This model is used in step 3 of the framework to generate inflow sequences with historical or perturbed characteristics for input to the hydrological simulation model of step 4. It allows the analyst to generate many years of synthetic data that have similar statistical properties to those of the flows in the historical hydrological series (or statistical properties perturbed according to climate change projections). In theory, the techniques used could be based on stationary or nonstationary autoregressive models of various types; see, e.g., Fiering and Jackson [1971] for the basic theory or Bras and Rodríguez-Iturbe [1993] for more up-to-date developments. Stakhiv [1998] provides

\footnotetext{
${ }^{1}$ Auxiliary materials are available in the HTML. doi:10.1029/ 2010WR009428.
}

an example of how these models can be used to assess scenarios of climate change.

[33] In the application described in this paper, 10,000 years of stationary monthly inflows were generated at 11 inflow nodes to the Nile system (depicted by the inflow arrows in Figure 5) for two climatic futures, one historical, and the other based on preprocessed projections of runoff from a single emissions scenario of climate change. For simplicity, a very basic multisite autoregressive model was selected [Fiering and Jackson, 1971]. This model preserves spatial cross correlations of monthly inflows across the 11 given inflow nodes in the system. Depending on the skewness of the distribution of each month's inflows at these 11 nodes, normal, lognormal, or constant-adjusted lognormal specifications were used; goodness-of-fit tests (Breusch-Godfrey and alternative Durbin tests) were then conducted to select between specifications with one to three lag terms. In the interest of space, the specific equations of 
the model are not presented here, but these have been made available in the auxiliary material. In general, the cumulative distributions of unperturbed synthetic inflows are very close to those of the historical inflows (available at most nodes for 50-70 years), and the temporal autocorrelation at each node is well preserved.

[34] Admittedly, there are a number of problems with using this approach for climate change scenario analysis. First, the statistical model assumes that flow stationarity holds over the flow period (here assumed to be 100 years). While it is possible to use streamflow generation procedures to account for nonstationarity, for simplicity the system was modeled as if it were stationary and experiencing a single changed climate condition. As a result, these flows are not feasible, and results pertaining to any given synthetic series cannot be considered to represent actual future outcomes. Nonetheless, the modeled perturbation can be used to explore the general consequences of mean changes in flow that are projected to be realistic at some point in the future, and thus help to inform the planner of how robust the system is to such mean changes. Thus, if the time horizon of interest is 50 years, the planner might consider projections of such changes at various points over the 50 year time horizon, to see how the system performance might change over the relevant time horizon. Another way of thinking about this is that relatively straightforward sensitivity analyses on changes in the mean of inflows provide valuable insights to planners and should probably generally be included in water resources planning processes.

[35] Second, the generation procedure would ideally preserve other statistical properties of flows besides the mean, variance and autocorrelation, i.e., skewness and autocorrelation [Fiering and Jackson, 1971]. However, such properties are also likely to change with (1) perturbations to the historical flow mean and variance and (2) climate change, as regional circulation patterns change. There has been limited research into the hydrological effect of shifts in autocorrelation or in the higher moments of the statistical distribution of runoff. The simple model used in this paper does not make any attempt to incorporate or control for these other types of changes.

\subsubsection{A Hydrological Simulation Model}

[36] The second model of the framework describes how the inflows enter and move through the water resources system, with and without new projects and/or operating regimes, and under changing climate conditions. The basic structure of this model is provided by the following flow continuity equations, adapted from Loucks et al. [1981]:

[37] For all nodes in the system (i.e., river nodes and lakes and reservoirs):

$$
\mathrm{S}_{s, t+1}=\mathrm{S}_{s, t}+\mathrm{Q}_{s, t}-\mathrm{R}_{s, t}-\mathrm{E}_{s, t}-\mathrm{L}_{s, t}-\mathrm{D}_{s, t},
$$

where

$S_{s, t}$ storage in the reservoir at site $s$ and time $t\left[\mathrm{~L}^{3}\right]$;

$Q_{s, t}$ inflow to the reservoir (or node) at site $s$ and time $t\left[\mathrm{~L}^{3}\right]$;

$R_{s, t}$ outflow from site $s$ at time $t\left[\mathrm{~L}^{3}\right]$;

$E_{s, t}$ net evaporation losses from site $s$ at time $t\left[\mathrm{~L}^{3}\right]$;

$L_{s, t}$ seepage (storage in groundwater) losses at site $s$ at time $t\left[\mathrm{~L}^{3}\right]$;

$D_{s, t}$ water withdrawal (for consumptive use, or partial consumption and return to the system further downstream) from site $s$ at time $t\left[\mathrm{~L}^{3}\right]$.
[38] These equations are written for a monthly time step $t$; all the variables in equation (1) are therefore monthly water volumes. For flow at modeled river nodes without storage infrastructures, the storage terms $S_{s, t}$ and $S_{s, t-1}$ and the evaporation and seepage terms $E_{s, t}$ and $L_{s, t}$ are set equal to zero, such that the constraint in equation (1) simplifies to

$$
\mathrm{Q}_{s, t}=\mathrm{R}_{s, t}+\mathrm{D}_{s, t}
$$

[39] Furthermore, inflows $Q_{s, t}$ are represented as the combination of outflows from the upstream site or node $s-1$ and the local increment to natural streamflow $\Delta F_{s, t}$ (or local runoff) between sites $s-1$ and $s$, as in the work by Cohon [1978]:

$$
\mathrm{Q}_{s, t}=\mathrm{R}_{s-1, t}+\Delta \mathrm{F}_{s, t}=\mathrm{R}_{s-1, t}+\mathrm{F}_{s, t}-\mathrm{F}_{s-1, t} .
$$

$\Delta \mathrm{F}_{s, t}$ is local runoff into the river at site $s\left[\mathrm{~L}^{3}\right] . F_{s, t}$ is volume of flow measured at gauging station at site $s$ over time increment $t\left[\mathrm{~L}^{3}\right]$.

[40] In this formulation, the local runoff $\Delta F_{s, t}$ is determined by calculating the difference in flow $F_{s, t}-F_{s-1, t}$ at adjacent nodes in the historical series. (It should be noted that this $\Delta \mathrm{Fs}, \mathrm{t}$ increment is not strictly equal to local runoff into the river between nodes $\mathrm{s}-1$ and $\mathrm{s}$, as it includes evaporation, seepage losses, and unmeasured consumptive use by people or industries located along the river. To the extent that these factors vary over time, there may be systematic bias in using this approach for predictive purposes). In the Nile Basin model, because there are also long river stretches in Sudan and Egypt over which there are no important sources of local runoff, flow calibration is enhanced using lag regression models applied to historical gauge records at adjacent nodes $s-1$ and $s$. Specifically, the observed flow in the historical record $F_{s, t}$ at node $s$ is expressed as some combination of $n$ lagged flow terms at nodes $s$ and $s-1$ :

$$
\begin{aligned}
\mathrm{F}_{s, t}= & \alpha_{s-1, t} \cdot F_{s-1, t}+\ldots+\alpha_{s-1, t-n} \cdot F_{s-1, t-n}+\alpha_{s, t-1} \cdot \mathrm{F}_{s, t-1} \\
& +\ldots+\alpha_{s, t-n} \cdot F_{s, t-n}+k_{s}
\end{aligned}
$$

where $\alpha_{j, t}$ is regression coefficient on flow at node $j$ and time $t$ [unitless] and $k_{s}$ is constant shift term obtained from regression model $\left[\mathrm{L}^{3}\right]$.

[41] The structure of this model and its calibration follow closely that of the Nile Decision Support Tool, or Nile-DST, developed at the Georgia Water Resources Institute [Yao and Georgakakos, 2003]. Figure 5 shows the model schematic; diagnostics pertaining to the calibration of the lag regression models using naturalized historical flows are available as auxiliary material. The model used for the research described in this paper has been configured to include additional storage and flow nodes to those in the Nile-DST, to allow input of either historical or synthetically generated inflows, to specify more possibilities for water withdrawals, and to modify design and operational attributes for new infrastructure projects. In addition, a number of functional relationships, referred to in this paper as physical linkages, have been created between climate variables and the terms in the continuity equations: (1) the effect of changes in temperature and precipitation on net evaporation from system lakes and reservoirs (changes in the term $E_{s, t}$ in equation (1) for all lakes and reservoirs); (2) temperature- 
induced changes in crop water requirements (changes in $D_{s, t}$ in equations (1) and (2); for all nodes where water demands exist, see Figure 5); and (3) the effect of precipitation changes on irrigation water requirements (again, changes in $D_{s, t}$ ). These functional linkages, as well as the economic linkages described further below, are explained in more detail in Text S1. Also, as pointed out by a reviewer, there are many physical and economic linkages that have not been included in the analysis. Some of these are explicitly mentioned further in section 6; future research should aim to explore their economic consequences just as this paper has studied the effects of six included linkages plus runoff changes.

[42] In using the framework to understand the behavior of a specific configuration of the system in a given climate condition, the analyst conducts repeated simulations for that configuration using the $n$ series of inflows (in this paper, the 10,000 years of flows generated by the stochastic generation procedure carried out in step 3 were divided into one hundred 100 year series). Each such simulation results in a unique set of system outputs. These unique series' of outputs can then be analyzed to obtain physical reliability measures that are often of interest to water resources engineers. For assessment of a new project or management strategy $p_{j}$, the system must be simulated twice, for the $p=0$ configuration and the $p=p_{j}$ configuration. Changes in overall system outputs with the new project can then be computed (in step 5 of the framework) relative to the baseline configuration for each of the unique inflow sequences. These incremental changes (e.g., in water demands met, hydropower produced in the system, and peak flood flows) provide understanding of the basin-wide consequences of different projects, and they are required inputs to the third, economic appraisal model.

\subsubsection{An Economic Appraisal Model}

[43] The economic appraisal model employs Monte Carlo simulation procedures to calculate project Net Present Value (NPV) under a wide range of possible physical and economic conditions. The effects of physical variability are transmitted through the $n$ sequences of incremental outputs pertaining to each unique inflow sequence and obtained from comparing with and without project configurations of the system. Economic uncertainty is transmitted through specified probability distributions of economic parameters in the valuation equations.

[44] Using Monte Carlo methods, the model then samples randomly from the unique sequences of incremental project outputs (in this case, from the one hundred 100 year series, each of which is assumed equally likely), and from the specified economic parameter distributions used to value those outputs. Each Monte Carlo trial yields a unique project NPV, obtained by aggregating the costs and benefits calculated for the values drawn for that trial:

$$
\mathrm{NPV}=\sum_{t=0}^{T}\left(B_{t}-C_{t}\right) \cdot r(t),
$$

where

$N P V$ sum of discounted net benefits, in monetary units;

$B_{t}$ sum of benefits in year $t$, in monetary units;

$C_{t}$ sum of costs in year $t$, in monetary units;

$r(t)$ discount factor in year $t$, assumed to be $1 /(1+\delta)^{t}$, representing a constant exponential discount factor with discount rate $\delta$.
[45] Because new projects can be added to the system at any point in the sequence of inflows, the NPV calculations can readily incorporate the time needed for construction and filling of a new reservoir, if the infrastructure is specified to be empty at the beginning of a simulation. Also, as in the hydrological simulation model, functional relationships, referred to in this paper as economic linkages, can be created between climate variables and the valuation parameters. This paper considers a few such linkages: (1) increases in the value of energy due to reduction of supply of or increasing demand for conventional energy sources; (2) changes in the value of water resulting from more or less constrained water supplies (due to inflow changes combined with growing demand for water in irrigation); and (3) the value of carbon offsets obtained from hydropower (see auxiliary material for details on the specification of these linkages).

[46] In this paper's application, 10,000 Monte Carlo trials are conducted to yield a distribution of NPV outcomes for the infrastructure option being considered, conditional on the observed natural variability, included climate linkages, and economic parameters specified in the scenario of interest.

\subsection{A Brief Digression: Interpretation Issues}

[47] Before describing the specific experiments conducted in this paper to illustrate the use of this proposed framework, a brief discussion of issues related to interpretation of results obtained from it is warranted. This discussion is important because analysts using the framework would need to consider the performance of projects or policies under a range of different possible future scenarios, defined in terms of changes in climate, water or energy demands, and/or any other dimensions.

[48] Traditional economic appraisal methods for water resources projects seek to quantify as best as possible all of their economic costs and benefits. Economists typically spend considerable effort parameterizing cost and benefit functions (i.e., demand and damage curves) based on the best available information at the time of planning, and use those functions to determine the expected net benefits of different investment options. Unfortunately, the climate change problem does not readily lend itself to calculation of expected net benefits, because the probabilities associated with different climate futures are unknown (making aggregation of outcomes across scenarios impossible). Plus, the stability of the economic relationships in a world with changing climate may be misrepresented, although this problem can be reduced if the parameters and functions in those relationships are allowed to be stochastic. The conceptual problem with conducting such traditional economic analysis emerges from several aspects of climate change, most notably that (1) accurate prediction of future emissions levels is not possible, especially given uncertainty about future mitigation; (2) the ranges of most changes caused by greenhouse gas emissions, both physical and economic, are highly uncertain; and (3) the impacts are likely to vary regionally and temporally in ways that are not well understood and/or predicted using climate models available today. Indeed, the type of uncertainty that results is very much like the "unmeasurable" or "true uncertainty" of the "nonquantitative" type that Knight [1921] described.

[49] Application of the simulation framework proposed in this research allows the planner to analyze the relative risks and upside potential of different infrastructure projects 
across a range of plausible climate and/or other future scenarios. Decision analytic tools could then be applied to help interpret the results across infrastructure options and scenarios. Such a full analysis for the Blue Nile is however beyond the scope of this paper. Here, the purpose is rather to demonstrate the types of linkages and uncertainties that can be considered using the proposed modeling approach. Nonetheless, some thoughts are offered for how multiscenario policy analysis could proceed in section 6 .

\section{Description of the Modeling Example}

[50] This section and section 5 describe an illustrative application of the hydroeconomic modeling framework to a potential large infrastructure project on the Blue Nile. The application described here does not comprise a policy analysis of Blue Nile development opportunities or even of this specific Blue Nile project. The aim is instead to show how the various linkages between climate and infrastructure performance can be included in the economic appraisal of projects, and to test whether or not these are likely to be important. The analysis likewise does not focus on the state of the art for producing projections from climate models, and only uses a single climate change scenario for comparison with the historical condition. The importance to project NPV of uncertainty in different economic and hydrological factors is then discussed.

[51] The Nile Basin is an interesting case study for several reasons. First, much of the Blue Nile upstream of Egypt and Sudan remains unregulated. A series of studies conducted by the U.S. Bureau of Reclamation in the 1950s and 1960s identified several attractive sites for large hydropower infrastructures in its upstream reaches (with regards to hydropower potential, surface-to-volume reservoir ratio, low potential for displacement of local populations, and low risk of earthquakes) [BCEOM et al., 1998; U.S. Bureau of Reclamation, 1964; Whittington et al., 2009]. Second, there is an opportunity for collaborative planning of Blue Nile water resources investments among Nile riparians due to increasing participation in the Nile Basin Initiative and a growing understanding that upstream regulation has the potential for generating system-wide benefits. Third, initial research on climate change suggests that arid and semiarid developing countries (such as those which make up the set of Nile riparians) are particularly vulnerable to the impacts of climate change [Abou-Hadid, 2006; Conway et al., 1996; Deressa, 2007; IPCC, 2007a; Strzepek and McCluskey, 2007]. New or existing infrastructures may play an important role in adaptation to climate change, but little practical research exists to guide planners in which aspects of water resources projects provide such adaptation benefits in economic terms. Finally, there is substantial uncertainty concerning how climate change will impact the Nile Basin [Conway and Hulme, 1996; Gleick, 1991; Sayed and Nour, 2006]. The effect that such uncertainty could have on the economics of new projects has not been considered systematically in the literature, either in specific applications, or in general.

\subsection{Approach}

[52] This paper reports on the individual and combined influence of the physical and economic climate change linkages described in section 3 on the NPV of one Blue Nile hydropower dam. A basin-wide model is necessary for this analysis because changes caused by the climate linkages and the addition of the new dam propagate through the full set of system continuity equations.

[53] For simplicity, the NPV of the project under historical conditions is compared only with a single scenario of climate change. The latter scenario is constructed based on ensemble mean projections for the A2 emissions scenario from the Intergovernmental Panel on Climate Change (IPCC). The two climate scenarios, historical and A2, are characterized by temperature, precipitation and inflows into the river system. Average historical values for temperature and precipitation are used to define the historical condition, and these are perturbed according to the A2 projections for the climate change scenario. In the historical condition, mean monthly inflows are set equal to those in the historical series. For the A2 scenario, monthly runoff is perturbed by the multimodel ensemble mean obtained from other work for 2050 [Strzepek and McCluskey, 2007], since the project time horizon is 75 years. Strzepek and McCluskey downscaled precipitation and temperature projections obtained from GCMs as input to a basic water balance model, to determine runoff from different Nile Basin subcatchments (see auxiliary material for further details). The stochastic inflow generator model is then used to produce series of inflows into the system at 11 points. This analysis also tests the sensitivity of results to a wider range of constant changes in system-wide inflows ( $15 \%$ decrease to $6 \%$ increase), informed by the magnitude of changes cited most frequently in the technical literature for this basin. Other moments and temporal and spatial correlation statistics of the inflows have not been changed.

[54] Both scenarios (historical and A2) assume the same level of irrigation and infrastructure development in the basin. Specifically, it is assumed that some additional irrigation development in the Eastern Nile will occur in Sudan and Ethiopia, consistent with aims expressed in country Master Plans (unpublished, internal documents). This development involves carrying out half of the Master Plan period projects in the Eastern Nile (Baro-Akobo, Blue Nile and Tekeze-Atbara catchments) plus some irrigation expansion along the Main Nile and Blue Nile in Sudan. Some of the expansion projects are currently underway, e.g., at Lake Tana in Ethiopia [World Bank, 2008] and around the Merowe Dam in Sudan [McDonald et al., 2009]. Total water withdrawals targets are summarized by country in Table 1.

\subsection{Reservoir Operating Rules}

[55] A potentially important limitation of the analysis in this paper is the assumption that the dam project would be operated based on operating rules developed for feasibility studies and designed to maximize hydropower generation while maintaining minimum river flows. There is no irrigation or water supply associated with this project because it is situated in a remote, uninhabitable canyon in Ethiopia, so the question of localized tradeoffs between water supply and hydropower do not apply. However, coordination of releases with demands in the downstream system (or lack thereof) could serve to alleviate (or worsen) downstream demand shortfalls. The economics of this type of downstream coordination have not been examined in this paper. In principle, such analysis could be conducted using the inte- 
Table 1. Key Parameters for the Economic Assessment of a Blue Nile Dam ${ }^{\mathrm{a}}$

\begin{tabular}{|c|c|c|c|}
\hline & Base Case Value & Sensitivity Range & Probability Distribution \\
\hline \multicolumn{4}{|l|}{ General model parameters } \\
\hline Target demand in Egypt ${ }^{\mathrm{b}}(\mathrm{bcm} / \mathrm{yr})$ & 55.5 & NA & NA \\
\hline Target demand in Sudan ${ }^{\mathrm{b}}$ (bcm/yr, baseline temperatures) & 16.1 & NA & NA \\
\hline Target demand in Ethiopia ${ }^{\mathrm{b}}$ (bcm/yr, baseline temperatures) & 3.4 & NA & NA \\
\hline Dam construction time (years) & 10 & NA & NA \\
\hline Dam project duration (years) & 75 & $30-100$ & Triangular \\
\hline Discount rate & 0.04 & $0.02-0.06$ & Uniform \\
\hline \multicolumn{4}{|l|}{ Cost components } \\
\hline Capital cost of dam (millions of U.S. dollars) & 2,750 & $2,200-3,300$ & Uniform \\
\hline Capital cost of transmission to Egypt (millions of U.S. dollars) & 800 & $640-960$ & Triangular \\
\hline Shadow value of capital & 1 & 1 & NA \\
\hline Construction delay (years) & 0 & $(-2)-2$ & Uniform, integer \\
\hline Renewal of electrical infrastructures (years) & 20 & None & NA \\
\hline $\mathrm{O}$ and $\mathrm{M}$ expenditures (As percent of annual capital cost) & 50 & $35-65$ & Triangular \\
\hline Cost of deficits (multiple of the value of downstream water) & 2 & $1-3$ & Triangular \\
\hline Number of households displaced & 120 & $60-340$ & Uniform \\
\hline Economic loss per displaced household (U.S. dollars) & 3,500 & $1,750-5,250$ & Triangular \\
\hline Area of downstream production lost: grazing + agriculture $(\mathrm{hA})$ & 25,000 & $12,500-37,500$ & Triangular \\
\hline Economic loss per hectare (U.S. dollars) & 20 & $10-100$ & Triangular \\
\hline Risk of catastrophic failure (\%) & 0.01 & $0.002-0.02$ & Uniform \\
\hline Project emissions (millions of tons of $\mathrm{CO}_{2}$ ) & 6.4 & $4.8-8.6$ & Triangular \\
\hline \multicolumn{4}{|l|}{ Benefit components } \\
\hline Hydropower generated at dam $(\mathrm{GWh} / \mathrm{yr})$ & Simmodel $^{\mathrm{c}}$ & NA & NA \\
\hline Installed capacity (MW) & 2,000 & NA & NA \\
\hline Net gain in hydropower in Sudan and Egypt (GWh/yr) & Simmodel $^{\mathrm{c}}$ & NA & NA \\
\hline Value of hydropower (U.S. cents $/ \mathrm{kWh}$ ) & 6.5 & $4-9$ & Uniform \\
\hline Change in timely irrigation water downstream (bcm/yr) & Simmodel $^{\mathrm{c}}$ & NA & NA \\
\hline Net value of timely water downstream (U.S. dollars/cm) & 0.075 & $0.025-0.15$ & Uniform \\
\hline Expected flood damage in Sudan ${ }^{\mathrm{d}}$ (millions of U.S. dollars/yr) & 8.8 & $4.4-17.6$ & Triangular \\
\hline Decrease in probability of flood $(\%)$ & Simmodel $^{\mathrm{c}}$ & NA & NA \\
\hline Price of offsets (U.S. dollars/ton $\mathrm{CO}_{2}$ ) & 20 & $10-30$ & Triangular \\
\hline Carbon offset factor & 0.52 & $0.3-0.6$ & Triangular \\
\hline \multicolumn{4}{|l|}{ Historical change parameters $(\% / \mathrm{yr}$, net of inflation) } \\
\hline Annual change in value of hydropower & 0 & $(-0.5)-0.5$ & Uniform \\
\hline Annual change in value of timely water & 0.5 & $0-1$ & Uniform \\
\hline \multicolumn{4}{|l|}{ A2 climate change parameters (\%/yr, net of inflation) } \\
\hline Annual change in value of hydropower & 0.5 & $0-1.5$ & Uniform \\
\hline Annual change in value of timely water & 1.0 & $0.5-1.5$ & Uniform \\
\hline Annual change in value of offsets & 0.5 & $0-1.5$ & Uniform \\
\hline
\end{tabular}

${ }^{\mathrm{a} N A}$, not applicable.

${ }^{\mathrm{b}}$ With A2 scenario temperature increases, these demands increase to $16.7 \mathrm{bcm} / \mathrm{yr}$ and $3.8 \mathrm{bcm} / \mathrm{yr}$ in Sudan and Ethiopia. Egyptian target demands remain at 55.5 as specified in the 1959 Nile Waters Agreement.

${ }^{c}$ Each 100 year series from the simmodel was assigned an integer label. A random draw from the uniform distribution of integers then determines which series is used in each of the 10,000 Monte Carlo trials.

${ }^{\mathrm{d}}$ Estimate from report done by Cawood et al. [2005].

grated framework by specifying rules for prioritization of different water demands (each with different economic values) above target releases for hydropower.

[56] Also, while it is likely true that water would need to be partitioned among users in the event of shortages, these deficits have been assumed to fall entirely on the irrigation sector in Sudan and Egypt, which have low water productivity [Perry, 1996; Wichelns, 1999]. The occasional shortages in the cases that have been modeled are relatively modest relative to legal country allocations, except in Sudan which has insufficient storage to meet its water demands in all years because of flow variability. In general, it appears reasonable to assume that the irrigation sector currently bears the cost of these water shortages.

\subsection{Parameters in the Economic Appraisal Model}

[57] The costs and benefits of a large Blue Nile hydropower project have been described in other research [Whittington et al., 2009]. This case study application uses similar data, largely obtained from unpublished, internal project studies and summarized in Table 1. For the economic appraisal calculations, highly uncertain parameters are assumed to be distributed uniformly over their possible ranges, because all values within the ranges are deemed equally plausible. A triangular distribution with peak probability at the expected value is assumed when data sources suggest that more confidence in expected parameter values is justified (for a description of the triangular distribution, see http://mathworld.wolfram.com/TriangularDistribution.html).

\section{Results}

[58] This section presents the results obtained from application of the integrated hydroeconomic assessment framework in this simple illustrative case. The first set of results presented here is similar to those yielded by the standard project appraisal methodology. The parameters in the valuation equations are assumed to be fixed (at their base case values; see Table 1) and known with certainty, and a single average hydrological flow series is used. The analysis is conducted for the project size recommended in pre- 
Table 2. Summary of Individual Linkage Experiments ${ }^{\mathrm{a}}$

\begin{tabular}{|c|c|c|c|c|c|c|c|c|c|c|}
\hline & $\mathrm{H}$ & $\mathrm{R}$ & $\mathrm{R}+\mathrm{NE}$ & $\mathrm{R}+\mathrm{CWT}$ & $\mathrm{R}+\mathrm{CWP}$ & All Physical & $\mathrm{R}+\mathrm{VH}$ & $\mathrm{R}+\mathrm{VW}$ & $\mathrm{R}+\mathrm{O}$ & All \\
\hline \multicolumn{11}{|c|}{ No Project Baseline System } \\
\hline System hydropower (GWh/yr) & 14,850 & 12,130 & 12,140 & 11,540 & 12,140 & 11,550 & 11,550 & 11,550 & 11,550 & 11,550 \\
\hline $\begin{array}{l}\text { Downstream deficits relative } \\
\text { to target withdrawals }(\mathrm{bcm} / \mathrm{yr})\end{array}$ & 1.0 & 1.4 & 1.4 & 2.0 & 1.4 & 2.0 & 2.0 & 2.0 & 2.0 & 2.0 \\
\hline Largest annual system deficit (bcm) & 14.7 & 20.7 & 20.5 & 22.2 & 20.5 & 22.3 & 22.3 & 22.3 & 22.3 & 22.3 \\
\hline $\begin{array}{l}\text { Percent of years countries cannot } \\
\text { meet target withdrawals }\end{array}$ & 99.7 & 100 & 100 & 100 & 100 & 100 & 100 & 100 & 100 & 100 \\
\hline Average monthly peak flow (bcm) & 13.6 & 12.8 & 12.8 & 12.7 & 12.8 & 12.7 & 12.7 & 12.7 & 12.7 & 12.7 \\
\hline \multicolumn{11}{|c|}{ System With Project } \\
\hline System hydropower (GWh/yr) & 25,080 & 21,330 & 21,240 & 20,640 & 21,340 & 20,560 & 20,560 & 20,560 & 20,560 & 20,560 \\
\hline $\begin{array}{l}\text { Downstream deficits relative } \\
\text { to target withdrawals }(\mathrm{bcm} / \mathrm{yr})\end{array}$ & 0.1 & 0.8 & 0.8 & 1.3 & 0.8 & 1.2 & 1.2 & 1.2 & 1.2 & 1.2 \\
\hline Largest annual system deficit (bcm) & 18.2 & 22.8 & 21.7 & 26.0 & 22.7 & 23.8 & 23.8 & 23.8 & 23.8 & 23.8 \\
\hline $\begin{array}{l}\text { Percent of years countries cannot } \\
\text { meet target withdrawals }\end{array}$ & 3.0 & 14.4 & 14.2 & 20.8 & 14.3 & 20.5 & 20.5 & 20.5 & 20.5 & 20.5 \\
\hline Average monthly peak flow (bcm) & 7.6 & 7.0 & 7.0 & 7.0 & 7.0 & 7.0 & 7.0 & 7.0 & 7.0 & 7.0 \\
\hline \multicolumn{11}{|c|}{ Economic Metrics for the Project } \\
\hline $\begin{array}{l}\text { Present value costs } \\
\text { (billions of U.S. dollars) }\end{array}$ & 3.6 & 3.6 & 3.6 & 3.6 & 3.6 & 3.6 & 3.6 & 3.6 & 3.7 & 3.7 \\
\hline $\begin{array}{l}\text { Present value benefits } \\
\text { (billions of U.S. dollars) }\end{array}$ & 10.8 & 9.0 & 8.9 & 8.7 & 9.0 & 8.6 & 10.5 & 8.9 & 10.6 & 11.6 \\
\hline NPV (billions of U.S. dollars) & 7.2 & 5.4 & 5.3 & 5.1 & 5.4 & 5.0 & 6.9 & 5.4 & 6.9 & 7.9 \\
\hline IRR (\%) & 10.6 & 9.5 & 9.4 & 9.4 & 9.5 & 9.3 & 10.2 & 9.5 & 10.4 & 10.8 \\
\hline $\begin{array}{l}\text { Total effect of linkage on } \\
\text { NPV (billions of U.S. dollars) }\end{array}$ & NA & -1830 & -90 & -300 & 5 & -2210 & 1500 & -20 & 1550 & 700 \\
\hline
\end{tabular}

${ }^{\mathrm{a}} \mathrm{H}$, historical conditions; CWP, precipitation changes over irrigated zones (A2 scenario); R, runoff only (A2 scenario); VH, increasing value of hydropower; NE, net evaporation (A2 scenario); VW, increasing value of water; CWT, temperature-linked crop water requirement (A2 scenario); $\mathrm{O}$, carbon offset; NPV, net present value; IRR, internal rate of return.

feasibility studies. The only difference between this analysis and standard appraisal methods, at least for the scenario with climate change, is that it explores the influence of the various physical and economic linkages discussed above. Next, the two stages of model simulations are used to incorporate uncertainty in both the economic and hydrological aspects of the planning problem; these generate a much wider range of possible NPV results. The section concludes with a sensitivity analysis to determine which uncertain parameters are most important in affecting economic outcomes.

\subsection{Effect of the Climate Change Linkages on Project Outcomes With Fixed Valuation Parameters}

[59] Under historical climate conditions, the project NPV is 7.2 billion U.S. dollars (IRR $=10.6 \%$ ) (Table 2, second column). The new dam contributes a great deal of new hydropower (about $10900 \mathrm{GWh} / \mathrm{yr}$ ) and also affects energy production from downstream reservoirs. Power output in Sudan increases, as a result of more regulated Blue Nile flow (Figure 6). On the other hand, power generation decreases at the High Aswan Dam (HAD) in Egypt due to somewhat lower storage levels in Lake Nasser. This lower storage in Lake Nasser is itself due to two factors: (1) storage of substantial amounts of water in the upstream reservoir and (2) increased irrigation withdrawals in Sudan as a result of flow regulation. Indeed, without upstream regulation, Sudan is generally unable to reach its demand target because of the irregular flow in the Blue Nile, such that overall system deficits decrease (by about 0.8 billion cubic meters (bcm) per year) with addition of the new project.

[60] The climate change linkages affect these calculations in several ways. Since the A2 scenario projections predict reduced runoff in the Blue Nile, the resulting decrease in streamflow has an important negative effect on the project economics (third column). This effect stems from lower hydropower production and a reduced ability of the dam to reduce demand shortfalls in the downstream system, even though system deficits still decrease (by $0.6 \mathrm{bcm} / \mathrm{yr}$ with addition of the dam). Under the modeled conditions, changes in net evaporation from Nile Basin reservoirs and lakes have only a slightly negative effect on the system (fourth column), because increased evaporation is mostly offset by greater rainfall over the large Equatorial lakes in the White Nile. Also, even though most withdrawals are downstream of the new dam, temperature-induced increases in crop water requirements result in higher irrigation demands in Sudan (from $16.1 \mathrm{bcm} / \mathrm{yr}$ to $16.7 \mathrm{bcm} / \mathrm{yr}$ ) and Ethiopia (from $3.4 \mathrm{bcm} / \mathrm{yr}$ to $3.8 \mathrm{bcm} / \mathrm{yr}$ ). This in turn decreases project NPV because more water is removed from the system, such that incremental effects on hydropower production and irrigation deficits furthest downstream are increased (fifth column). The effect of the final linkage, changes in precipitation over irrigated lands, on the calculations is small (sixth column), because most of the irrigation in the Nile Basin is in arid lands, and changes in precipitation have a minor effect on the calculations.

[61] When all physical linkages are combined (Table 2, seventh column), NPV is reduced to 5.0 billion U.S. dollars (IRR $=9.4 \%)$. This decrease results from same three factors mentioned above: (1) reduced hydropower production in the new dam (10100 GWh/yr, compared to the 10890 under historical conditions) (Figure 6); (2) downstream reduction in hydropower produced from the High Aswan Dam; and (3) the increase in unmet target water demands in the 


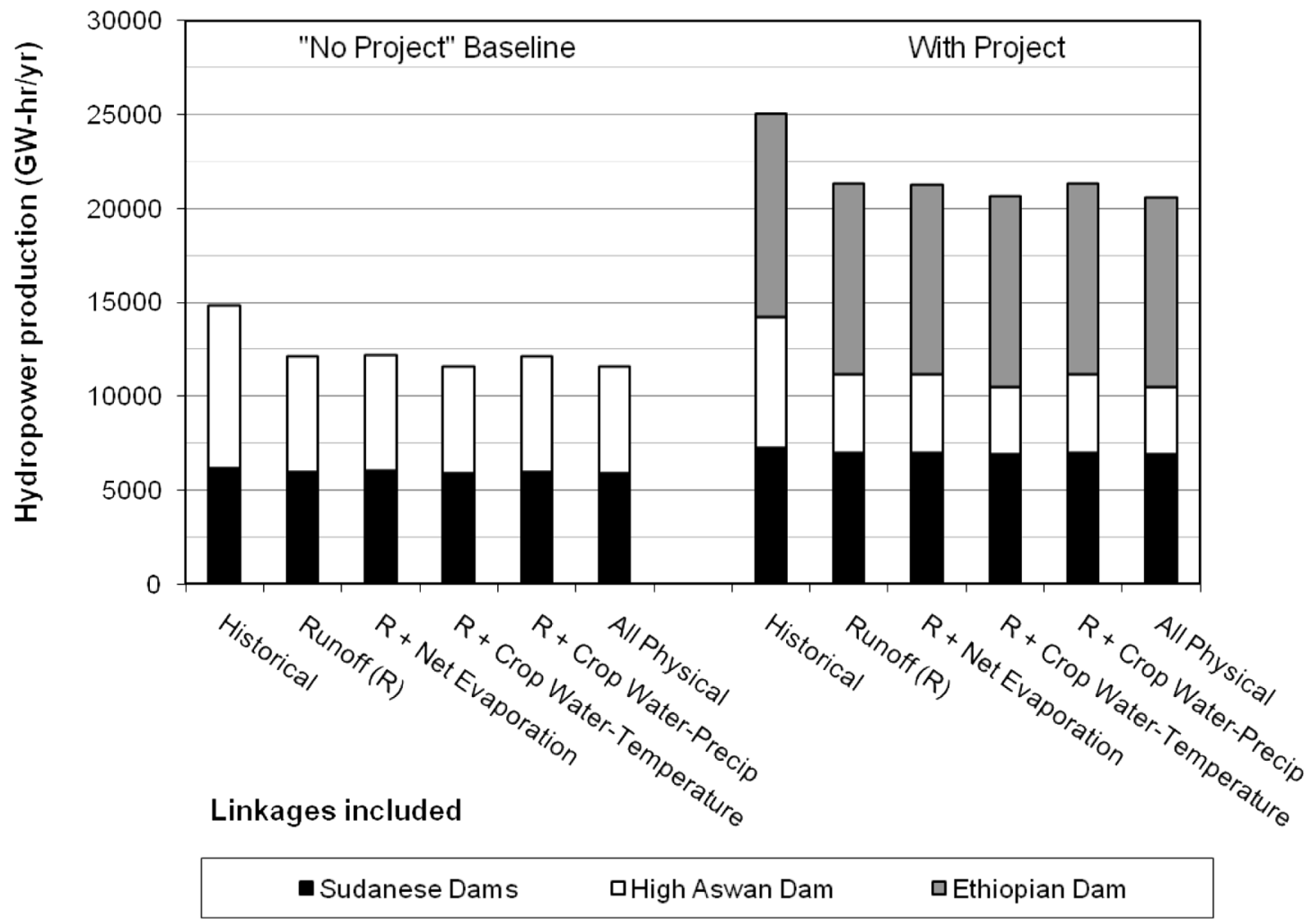

Figure 6. The effect of the climate change linkages on hydropower production in Sudan, at the High Aswan Dam in Egypt and at the new Ethiopian hydropower site (R stands for inclusion of the runoff change linkage).

downstream system due to higher temperatures. Under historical conditions, the regulated flow from the Blue Nile Dam enables Sudan to meet target demands without affecting the irrigation furthest downstream. With A2 scenario temperature and crop water demand increases, Blue Nile flow regulation due to the dam project still allows Sudan to achieve its target withdrawals. This increased level of upstream abstractions, however, somewhat increases deficits furthest downstream.

[62] One important point is that these shifting deficits result from model assumptions that do not prioritize water use in any particular location; that is, the precise location of these demand shortfalls could in reality be quite different since these could be shared among riparians. Still, it is possible that climate change could impact water availability such that existing plans for irrigation expansion require water abstractions that cannot be maintained over the long term. Upstream storage appears to have the potential to reduce total deficits in the system, but only cooperation among riparians would ensure that reservoir releases could be managed most effectively.

[63] In contrast to the physical linkages, the economic linkages increase the value of the project. This is because of the hypothesized positive link between climate change and the real value of hydropower. A Blue Nile dam easily provides enough energy to outweigh decreases in power generated downstream (eighth column). Also, carbon offsets at this site outweigh estimated construction and reservoir emissions and therefore also contribute to increasing net benefits (tenth column). The assumed increase in the value of water over time (due to increased water demand and reduced supply) only slightly raises the value of the dam because the project has only a modest impact on system deficits (ninth column). The net positive effect of the economic linkages results in a project NPV of 7.9 billion U.S. dollars (IRR $=10.8 \%$ ) when all linkages are included (eleventh column), which is slightly higher than the NPV assuming historical conditions.

\subsection{Results of the Integrated Hydroeconomic Simulations: Effects of Uncertainty}

[64] Consistent with these results with fixed valuation parameters, the economic simulations that instead allow these parameters to vary over the ranges in Table 1 reveal that the linkages with lower inflow and temperature-related increases in crop water requirements both shift the distribution of possible NPV outcomes to the left (Figure 7a). For the decrease in runoff, the shift is about 2.0 billion U.S. dollars at the median of the distribution (2.1 billion U.S. dollars at the mean), but very few (only 1.7\%) simulations result in negative NPV. The increased crop water requirements (from rising temperature) in the system shifts the distribution an additional -340 million U.S. dollars at the median ( -280 at the mean), and the percentage of simulations that yield negative NPV is $3.0 \%$. The other physical linkages have a small negative impact on the NPV distributions. The cumulative effect of all physical linkages is thus a decrease of 2.4 billion U.S. dollars at the median of the NPV distribution (2.6 at the mean) relative to historical 


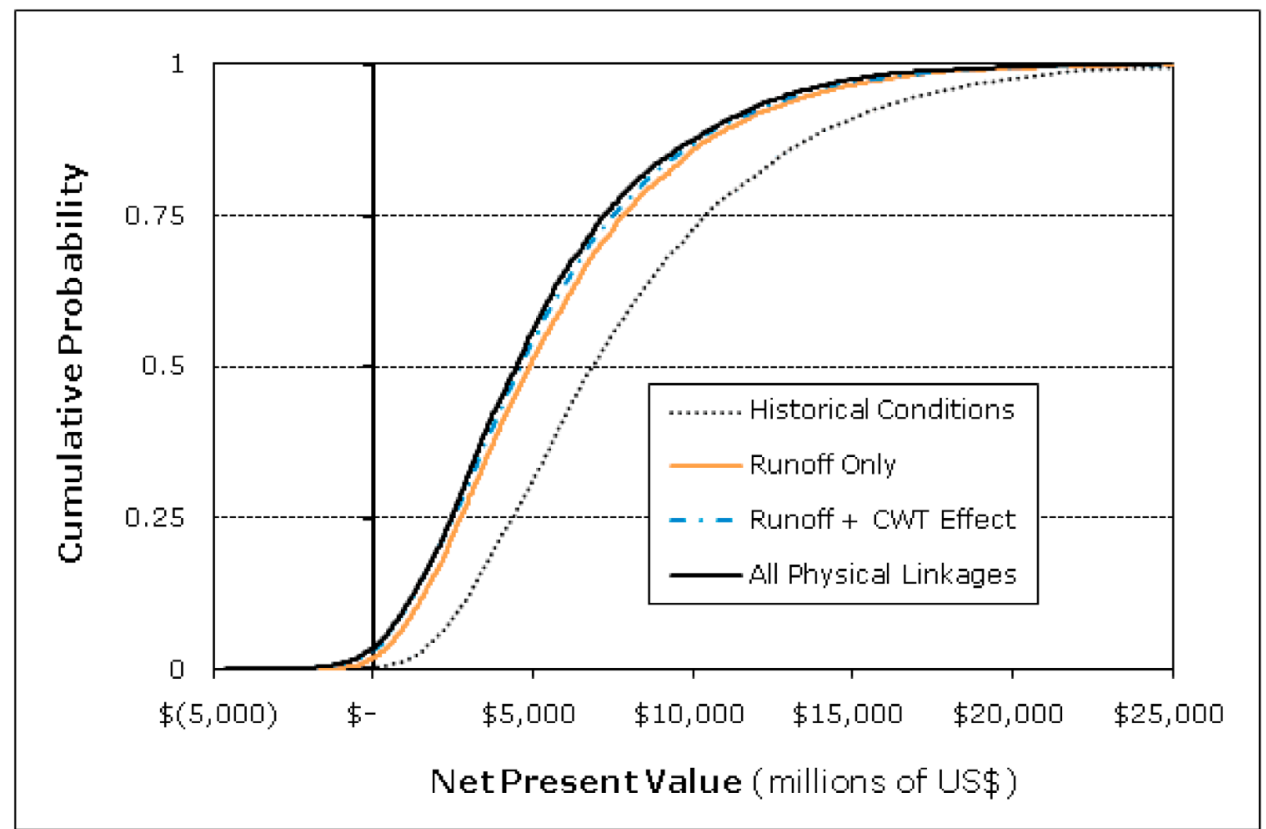

A

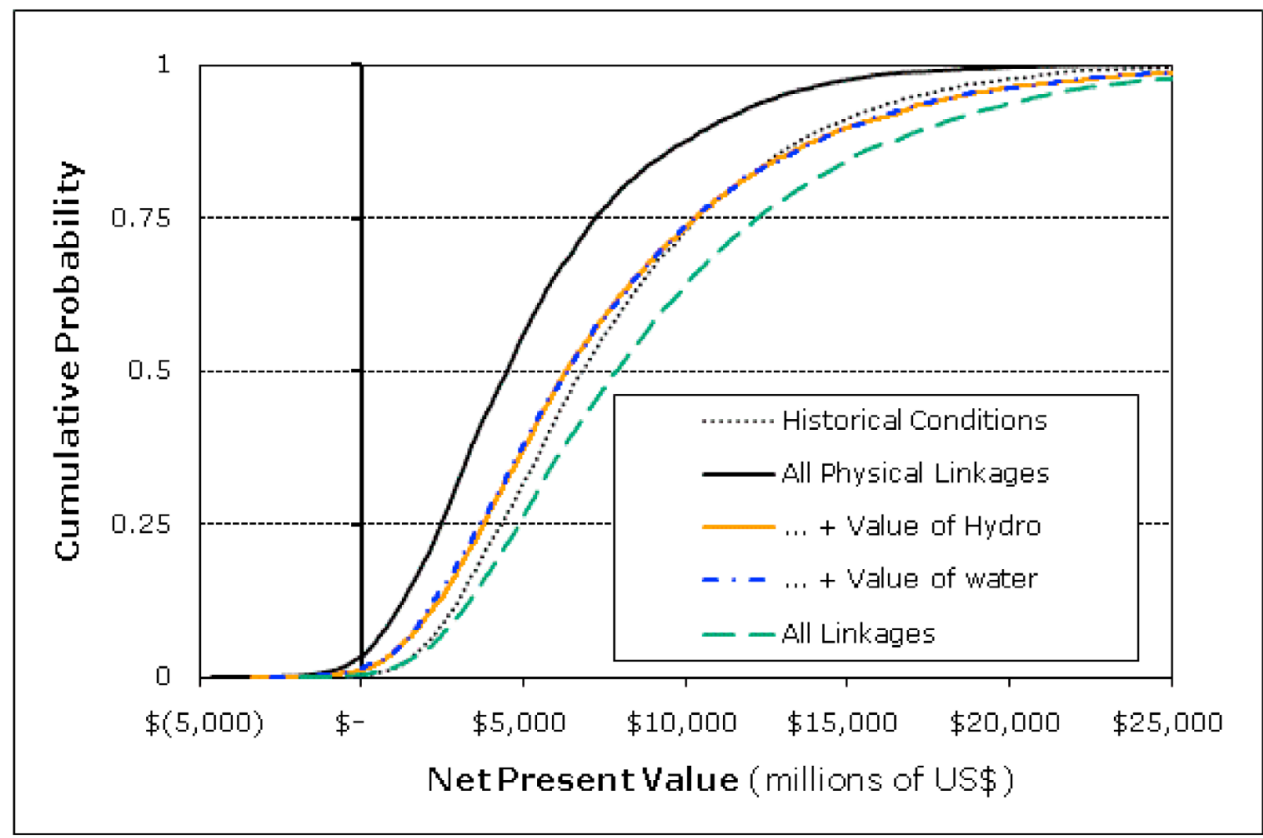

B

Figure 7. The cumulative effect of (a) the physical and (b) the economic climate change linkages on the NPV outcomes of the Blue Nile Dam project (results of 10,000 Monte Carlo trials; CWT stands for inclusion of the crop water to temperature linkage).

conditions, and $3.4 \%$ of simulations yield a negative project NPV, compared with $0.2 \%$ in the historical case.

[65] Also similar to the analysis with fixed valuation parameters, the effect of the economic climate change linkages is mostly to increase the economic value of the Blue Nile Dam (Figure 7b). Including increases in the real value of hydropower shifts the median of the distribution to the right by about 1.8 billion U.S. dollars ( 2.5 at the mean), and decreases the percentage of simulations with negative NPV outcomes to about $1.1 \%$. The increased real value of water has a minor impact of +20 million U.S. dollars at the median
( -50 at the mean). Finally, including the value of carbon offsets in the economic analysis shifts the distribution to the right by an additional 1.5 billion U.S. dollars at the median (1.6 at the mean). Once all linkages are included, only $0.3 \%$ of simulations yield negative NPV outcomes, and the economic value of the dam is higher than under historical conditions in over $96 \%$ of the simulations (Figure $7 \mathrm{~b}$ ). These results suggest that a Blue Nile hydropower dam may provide adaptation benefits to the region, at least under these particular conditions. Negative economic outcomes here only occur with an unlikely convergence of negative factors: 


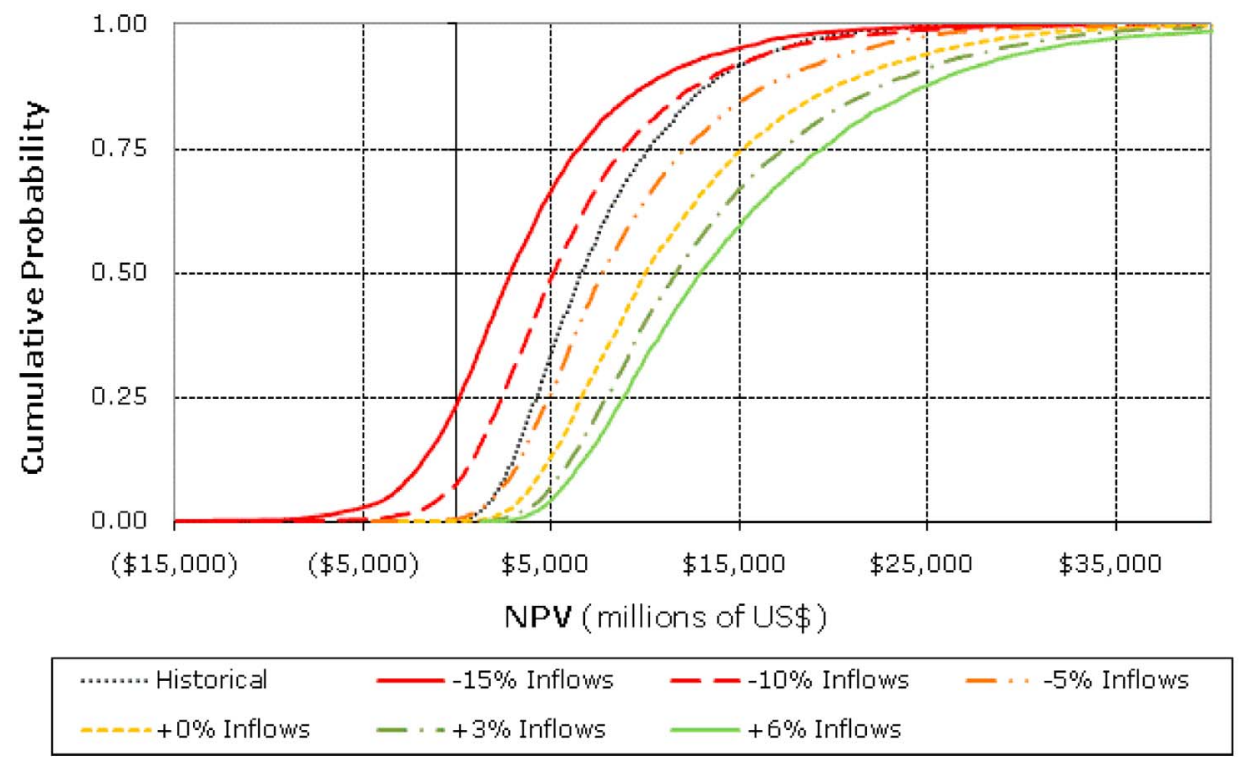

Figure 8. The effect of inflow variation on the NPV outcomes of the Blue Nile Dam project (results of 10,000 Monte Carlo trials).

extended periods of reduced flows from the Blue Nile coupled with large increases in the relative cost of irrigation demand shortfalls, a low value of carbon offsets and hydropower, as well as capital costs that are much higher than expected. Also importantly, these simulations reveal that there is a large spread of potential economic outcomes from the project, ranging from an NPV of close to zero to very large NPV outcomes of nearly 25 billion U.S. dollars. This large spread is what conventional water resources project appraisal techniques tend to miss.

\subsection{Additional Sensitivity Analysis}

[66] Given this large spread and the particularly strong negative effect of reduced (and highly uncertain) runoff in the river, additional sensitivity analyses were conducted over a wider range of inflow changes, including all climate linkages and the A2 scenario temperature projections. These experiments show that economic outcomes are highly sensitive to changes in inflows (Figure 8). The span in median NPV across the range of inflow sensitivity scenarios, from $-15 \%$ to $+6 \%$, is about 10 billion U.S. dollars $(-15 \%$ inflows median NPV $=2.9$ billion U.S. dollars; $+6 \%$ median $\mathrm{NPV}=12.9$ billion U.S. dollars). Also, the point at which the dam's value decreases from the historical climate condition is somewhere between a $5 \%$ and $10 \%$ decrease in system inflows. If flow were to decrease by $15 \%$ in the Nile Basin, the simulations show that it is somewhat likely that the Blue Nile Dam project would not pass a cost-benefit test $(21 \%$ of simulations yield a negative NPV outcome), though median and mean NPV outcomes remain positive. On the other hand, if flows increase by $6 \%$ or even stay the same, the project would pass a cost-benefit test under most conditions.

[67] Thus, in this particular application, changes in inflows do more to change outcomes than the inclusion of the other physical climate change linkages, which sum to -0.1 billion U.S. dollars at the median (Figure 7). The linkages with the strongest influence on economic out- comes are the negative effect of increasing crop water demand ( -0.3 billion U.S. dollars) and the positive effects of the increased real value of hydropower $(+1.5$ billion U.S. dollars) and carbon offsets ( +1.6 billion U.S. dollars).

[68] Other parameters in the economic appraisal model also have an important effect on project NPV, though no single parameter is sufficient to induce a negative project NPV on its own (Figure 9). These parameters are: the discount rate (see Jeuland [2010] for a more in-depth discussion of the problem of discounting for project appraisal in the context of climate change), the value of energy (both base hydropower value and percent change in real value over time), the length of the time horizon, natural hydrological variability (determined by the stochastic sequence number that is randomly selected for the simulation), the value of downstream irrigation water, and construction delays. Comparing Figures 9a and 9b, it becomes clear that many of the same parameters contribute to the variation in outcomes under historical and A2 scenario conditions. However, the uncertainty associated with climate-perturbed inflows (spanning 10 billion U.S. dollars) is second only to the discount rate, which alone alters the dam's economic value by 14.0 billion U.S. dollars in the climate change scenario). The inability of current modeling techniques to predict runoff precisely therefore represents a significant source of uncertainty in the economics of Blue Nile hydropower infrastructures. Not surprisingly, the other parameter that contributes to a large change in outcomes (third in importance; spanning 8.3 billion U.S. dollars) is the value of energy.

\section{Discussion}

[69] In this particular application of a new, integrated hydroeconomic simulation framework for conducting appraisal of water resources projects, it was shown that uncertainties associated with a variety of unknown and/or variable economic and physical parameters can combine to have a very significant impact on calculations of project Net 

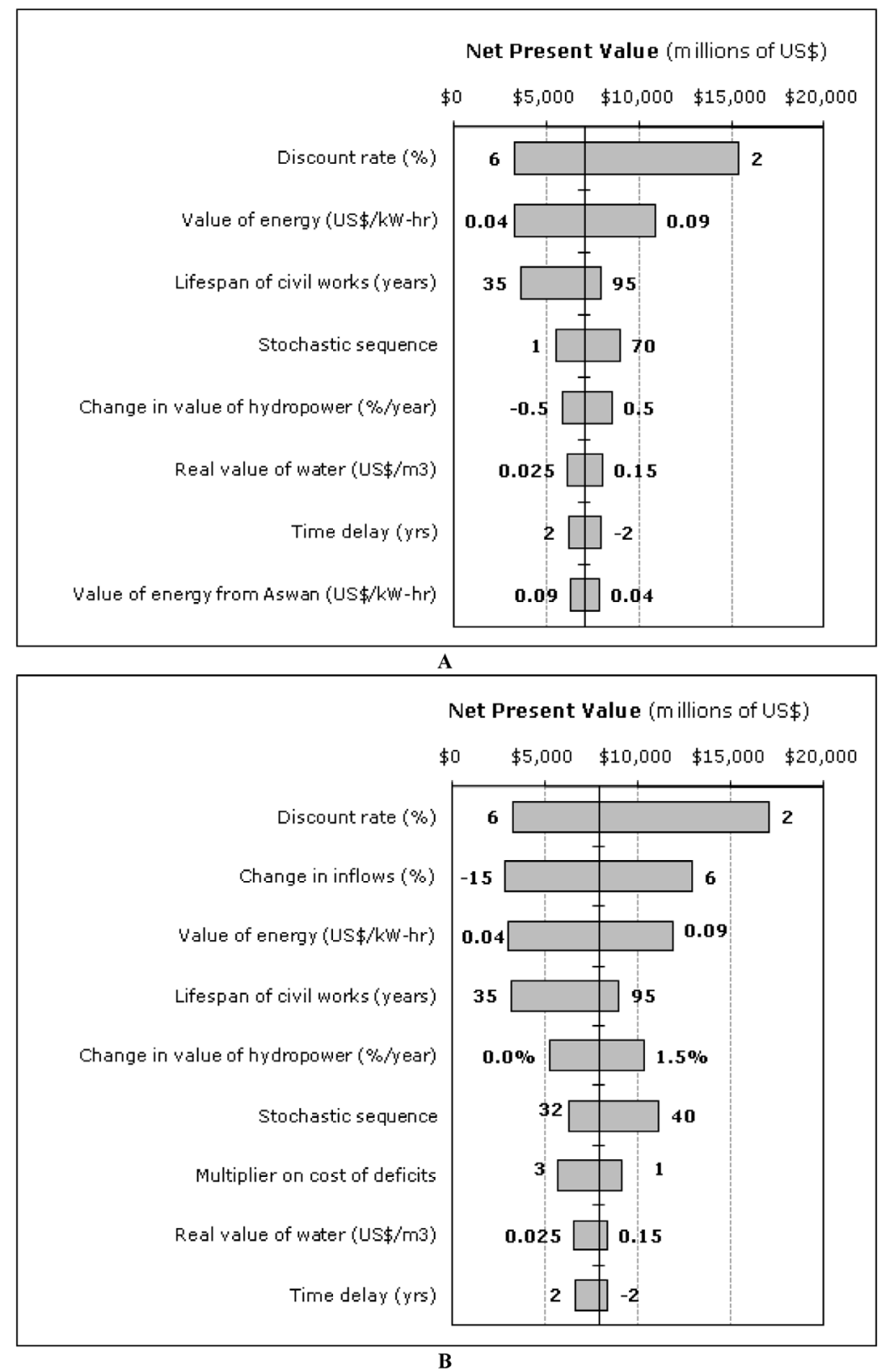

Figure 9. The effect of individual parameters on the net present value of the project under (a) historical and (b) A2 climate conditions, with median outcome indicated by the solid black line. The numbers shown at the ends of the bars indicate the upper and lower bounds on assumed parameter values, to which the displayed NPV ranges correspond.

Present Value. Plausible and modest changes in mean inflows, which are impossible to know precisely given the state of climate change science today, were second only to the discount rate (itself a controversial parameter as well, especially in the context of climate change) in shifting NPV outcomes. Other parameters that had a large effect on project NPV were the value of energy generated in the system, the length of the planning horizon, the natural hydrological variability in the Blue Nile, the value of downstream irrigation water, and the problems posed by construction delays. The individual physical climate change linkages were relatively less important than inflow changes, but an increase in crop water requirements due to climate change was shown to have important physical consequences in this system, via its effect on the availability of water in the downstream system.

[70] It would be incorrect to use the results of this paper to argue that the specific climate linkages modeled here are either complete or represent the most important effects in the Nile or in other river basins. A number of linkages have not been included (recall Figure 1) or have only been included in superficial ways. For example, the effect of rising temperature and changing precipitation on evapotranspiration of nonirrigated vegetation could have very significant impacts on soil moisture and subsequent runoff in the basin, effects which have been ignored here. Importantly, feedbacks 


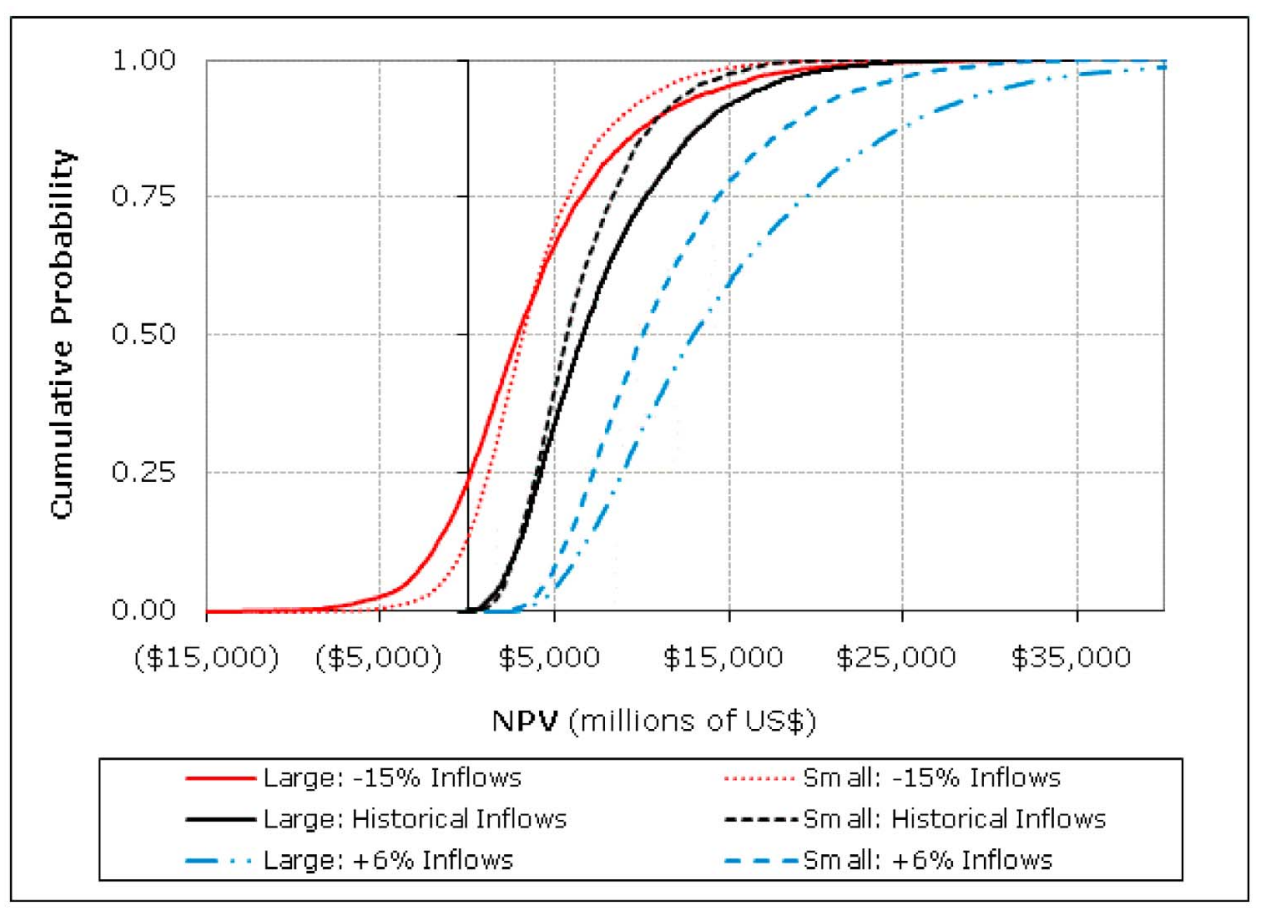

Figure 10. Comparison of small versus large project NPV under three possible future inflow conditions (results of 10,000 Monte Carlo trials).

between water availability or economic factors (such as the value of water or energy) and the irrigation "demands" in the system, have not been modeled. The quantity of water demanded is in reality simultaneously determined by supply and demand. Thus, demand deficits may be overstated, since irrigators or other farmers would likely adapt to changes in water availability, perhaps by switching cropping patterns, increasing or decreasing irrigated areas, changing farming and irrigation technology, etc. Policy makers might also intervene, by changing food security and import policies, or pricing of water and incentives in water-consuming sectors more generally. There is no reason why such linkages could not be included in the analytical framework presented here, but additional work would be required to obtain a reasonable functional representation in any particular location or setting.

[71] This analysis was meant to illustrate a methodological approach for integrating climate change into the conventional reservoir planning problem, and should not be considered a full economic appraisal of this project. To be viewed as such, the analysis would need to satisfy additional requirements, including, e.g., (1) more detailed analysis of the distributive impacts of the project, (2) consideration of different designs and operating rules (i.e., coordination of releases with downstream irrigation or other water supply requirements) for the infrastructure in question, (3) assessment of the economics of alternative projects, and (4) the performance of these projects across a wide variety of plausible future climate conditions. The reader should be reminded that the analysis assumed that the Blue Nile Dam would be operated based on proposed operating rules designed to maximize hydropower production. Coordination with downstream demands or storage levels in Lake Nasser would surely allow greater reduction of downstream demand shortfalls under climate change, though this would come at the cost of reduced hydropower generation. Similarly, combinations of dams might provide synergies in (or increase risks associated with) hydropower-based development. In addition, the economics of different rules for sharing deficits have not been analyzed. The tradeoffs in costs and benefits and shadow prices for water under different coordination strategies have not been assessed in this research.

[72] Also, it is possible that no project in the choice set of alternatives will perform best in all plausible future scenarios (recall that this has been a common critique of optimization-based planning models). To illustrate this point, consider results from a very simple comparison of the infrastructure modeled here with a smaller dam design (Figure 10). If it was known that system inflows would decrease by $15 \%$, risk-averse policy makers might opt for a smaller, less expensive dam option. The median NPV for this design is 3.1 billion U.S. dollars compared to 2.8 U.S. dollars for the larger option, and the percentage of negative NPV outcomes is about $13 \%$, compared with $25 \%$ for the larger option (not to mention that the magnitude of negative NPV outcomes is much less). On the other hand, for the historical case or increased future inflows, the NPV distributions for the larger design, which produces more hydropower, dominate that of the smaller design. In such a future, selection of a smaller dam would have resulted in major foregone benefits. Of course, the problem is that future climate-affected inflows are unknown. In such cases, decision-analytic tools can help policy makers to select solutions that are both robust to key uncertainties and maintain the possibility of high economic gains. Depending on their objectives, policy makers might use conservative decision rules that minimize downside risk across the universe of possible climate scenarios, implement risk-taking 
strategies that maximize potential future upside, or choose rules that somehow balance these objectives. Real options theory can also help to guide decision makers toward thinking about how design features (siting, sizing, creating redundancies, timing) and flexible operating regimes (institutional and structural) can improve project outcomes.

\section{Conclusions}

[73] This research demonstrated the use of a hydroeconomic framework for assessing the economic value of new infrastructures when future climatic, hydrological and economic conditions are highly uncertain. The novel aspect of this research is its exploration of the simultaneous influence of a number of physical and economic effects of climate change on project Net Present Value: physical changes in runoff, net evaporation from reservoirs, and crop water requirements in irrigation, as well as economic changes in the value of water and energy, and the value of carbon offsets.

[74] An important goal of the research was to learn about the importance of including such linkages when conducting project assessments. In this application, four of the modeled linkages proved noteworthy: changes in runoff, crop water requirements, the changing value of energy, and the inclusion of carbon offset value. Another important result was the finding that the linkages may have compensating effects. It was shown that decreases associated with physical linkages and reduced runoff could in this case be offset by increased benefits from higher energy values and the inclusion of carbon offset value. The overall effect of modeling the linkages was to increase the percentage of outcomes at the upper end of the cumulative NPV distribution. It thus seems possible that a Blue Nile dam could provide greater benefits under climate change than in the historical condition.

[75] Still, it is an empirical question where different linkages will be most important, and research is clearly needed to better understand them. Data permitting, attempts should thus be made to identify, understand, and build such functional relationships into water resources models, to better explore where they are likely to be important, and how natural and economic feedbacks may influence outcomes. The roles of adaptation in the agriculture sector, population migration, and land degradation, e.g., have scarcely been considered in water resources planning.

[76] Acknowledgments. Thanks are due to members of the World Bank and the Eastern Nile Technical Regional Office in Addis Ababa, with whom the author had many useful discussions about this research and the process of planning infrastructure projects in the Blue Nile. Dale Whittington, Donald Lauria, Gregory Characklis, Mohamed Abdel-Aty Sayed, Nagaraja Harshadeep, and Harvey Jeffries all provided useful comments on earlier versions of this work. Other colleagues who provided useful comments and support include Abdulkarim Seid, Ahmed Khalid Eldaw, Yohannes Daniel, Ken Strzepek, Alyssa McCluskey, Casey Brown, Declan Conway, and many others. Thanks are also due to the anonymous reviewers of this paper. The author is solely responsible for any errors that remain.

\section{References}

Abou-Hadid, A. F. (2006), Assessment of impacts, adaptation, and vulnerability to climate change in North Africa: Food production and water resources, 127 pp., Int. START Secr., Washington, D. C.
Arnell, N. (2004), Climate change and global water resources: SRES emissions and socio-economic scenarios, Global Environ. Change, 14(1), 31-52, doi:10.1016/j.gloenvcha.2003.10.006.

BCEOM, et al. (1998), Part 1: Main report-Water resources studies, in Abbay River Basin Integrated Development Phase 3 Master Plan Project, Minist. of Water Resour., Fed. Democratic Repub. of Ethiopia, Addis Ababa.

Bouwer, H. (2002), Integrated water management for the 21st century: Problems and solutions, J. Irrig. Drain. Eng., 128, 193-202, doi:10.1061/(ASCE)0733-9437(2002)128:4(193).

Bras, R. L., and I. Rodríguez-Iturbe (1993), Random Functions and Hydrology, 559 pp., Courier Dover, Mineola, N. Y.

Cawood, M., et al. (2005), An initial rapid appraisal of flood damages along the Blue and main Nile rivers in Sudan, draft report, 34 pp., Michael Cawood and Assoc. Prop., Melbourne, Vic., Australia.

Cohon, J. L. (1978), Multiobjective Programming and Planning, Academic, San Diego, Calif.

Conway, D., and M. Hulme (1996), The impacts of climate variability and future climate change in the Nile Basin on water resources in Egypt, Int. J. Water Resour. Dev., 12(3), 277-296, doi:10.1080/07900629650178.

Conway, D., et al. (1996), Future availability of water in Egypt: The interaction of global, regional, and basin scale driving forces in the Nile Basin, Ambio, 25(5), 336-342.

Davies, H., and R. Walsh (1997), Historical changes in the flood hazard at Khartoum, Sudan: Lessons and warnings for the future, Singapore J. Trop. Geogr., 18(2), 123-140, doi:10.1111/1467-9493.00012.

Deressa, T. T. (2007), Measuring the Economic Impact of Climate Change on Ethiopian Agriculture: A Ricardian Approach, 32 pp., doi:10.1596/ 1813-9450-4342, World Bank, Washington, D. C.

Eckstein, O. (1958), Water-Resource Development: The Economics of Project Evaluation, Harvard Univ. Press, Cambridge, Mass.

Fiering, M. B., and B. B. Jackson (1971), Synthetic Streamflows, Water Resour. Monogr. Ser., vol. 1, AGU, Washington, D. C.

Frederick, K. D., and D. C. Major (1997), Climate change and water resources, Clim. Change, 37(1), 7-23, doi:10.1023/A:1005336924908.

Frederick, K. D., et al. (1997), Climate Change and Water Resources Planning Criteria, 316 pp., Kluwer Acad., Dordrecht, Netherlands.

Gleick, P. H. (1991), The vulnerability of runoff in the Nile Basin to climate changes, Environ. Prof., 13, 66-73.

Hanemann, W. M. (1992), Preface, in Pricing the European Environment, edited by S. Navrud, pp. 9-36, Scandinavian Univ. Press, Oslo.

Harou, J. J., et al. (2009), Hydro-economic models: Concepts, design, applications, and future prospects, J. Hydrol., 375(3-4), 627-643, doi:10.1016/j.jhydrol.2009.06.037.

Hassan, F. (1981), Historical Nile floods and their implications for climatic change, Science, 212(4499), 1142-1145, doi:10.1126/science. 212. 4499.1142

Hufschmidt, M. M., and M. B. Fiering (1966), Simulation Techniques for Design of Water-Resource Systems, Harvard Univ. Press, Cambridge, Mass.

Inter-Agency River Basin Committee (1950), Proposed Practices for Economic Analysis of River Basin Projects, Sub-Comm. on Costs and Budgets, Washington, D. C.

Intergovernmental Panel on Climate Change (IPCC) (2007a), Climate Change 2007: Impacts, Adaptation and Vulnerability: Contribution of Working Group II to the Fourth Assessment Report of the Intergovernmental Panel on Climate Change, Cambridge Univ. Press, New York.

Intergovernmental Panel on Climate Change (IPCC) (2007b), Climate Change 2007: The Physical Science Basis: Contribution of Working Group I to the Fourth Assessment Report of the Intergovernmental Panel on Climate Change, edited by S. Solomon et al., Cambridge Univ. Press, New York.

Jeuland, M. (2010), Social discounting of large dams with climate change uncertainty, Water Alternatives, 3(2), 185-206.

Knight, F. L. (1921), Risk, Uncertainty and Profit, Houghton Mifflin, Boston, Mass.

Krutilla, J. V., and O. Eckstein (1958), Multiple Purpose River Development, Johns Hopkins Press, Baltimore, Md.

Leavesley, G. H. (1999), Overview of models for use in the evaluation of the impacts of climate change on hydrology, in Impacts of Climate Change and Climate Variability on Hydrological Regimes, edited by J. C. van Dam, pp. 107-122, doi:10.1017/CBO9780511564499.009, Cambridge Univ. Press, Cambridge, U. K.

Lettenmaier, D. P. (2008), Editorial: Have we dropped the ball on water resources research?, J. Water Resour. Plann. Manage., 134, 491-492, doi:10.1061/(ASCE)0733-9496(2008)134:6(491). 
Lettenmaier, D. P., et al. (1999), Water resources implications of global warming: A U.S. regional perspective, Clim. Change, 43(3), 537-579, doi:10.1023/A:1005448007910.

Loucks, D. P., et al. (1981), Water Resource Systems Planning and Analysis, Prentice-Hall, Englewood Cliffs, N. J.

Loucks, D. P., et al. (2005), Water Resources Systems Planning and Management: An Introduction to Methods, Models and Applications, UNESCO, Paris.

Maass, A., et al. (1962), Design of Water-Resource Systems: New Techniques for Relating Economic Objectives, Engineering Analysis, and Governmental Planning, Harvard Univ. Press, Cambridge, Mass.

Marchant, R., and H. Hooghiemstra (2004), Rapid environmental change in African and South American tropics around 4000 years before present: A review, Earth Sci. Rev., 66(3-4), 217-260, doi:10.1016/j.earscirev. 2004.01.003.

McDonald, K., et al. (2009), Exporting dams: China's hydropower industry goes global, J. Environ. Manage., 90, S294-S302.

Milly, P. C. D., et al. (2005), Global pattern of trends in streamflow and water availability in a changing climate, Nature, 438(7066), 347-350, doi:10.1038/nature04312.

Nicholson, S. E. (2001), Climatic and environmental change in Africa during the last two centuries, Clim. Res., 17(2), 123-144, doi:10.3354/cr017123.

Nicholson, S. E., and X. Yin (2001), Rainfall conditions in equatorial East Africa during the nineteenth century as inferred from the record of Lake Victoria, Clim. Change, 48(2-3), 387-398, doi:10.1023/ A:1010736008362.

Perry, C. J. (1996), Alternative approaches to cost sharing for water service to agriculture in Egypt, Res. Rep. 2, Int. Irrig. Manage. Inst., Colombo, Sri Lanka.

ReVelle, C., and A. E. McGarity (1997), Design and Operation of Civil and Environmental Engineering Systems, Wiley Intersci., New York.

Rogers, P. P., and M. B. Fiering (1986), Use of systems analysis in water management, Water Resour. Res., 22, 146S-158S, doi:10.1029/ WR022i09Sp0146S.

Sayed, M. A., and M. Nour (2006), Impacts of climate change on Nile flows, 19 pp., East. Nile Tech. Reg. Off., Addis Ababa.

Shahin, M. (1985), Hydrology of the Nile Basin, Elsevier Sci., Amsterdam.

Stakhiv, E. Z. (1998), Policy implications of climate change impacts on water resources management, Water Policy, 1(2), 159-175, doi:10.1016/S13667017(98)00018-X.
Sterner, T., and U. M. Persson (2008), An even sterner review: Introducing relative prices into the discounting debate, Rev. Environ. Econ. Policy, 2(1), 61-76, doi:10.1093/reep/rem024.

Strzepek, K., and A. McCluskey (2007), The Impacts of Climate Change on Regional Water Resources and Agriculture in Africa, 62 pp., World Bank, Washington, D. C.

U.S. Bureau of Reclamation (1964), Land and Water Resources of the Blue Nile Basin: Main Report and Appendices I-V, U.S. Dep. of the Inter., U.S. Gov. Print. Off., Washington, D. C.

Vicuna, S., and J. A. Dracup (2007), The evolution of climate change impact studies on hydrology and water resources in California, Clim. Change, 82(3-4), 327-350, doi:10.1007/s10584-006-9207-2.

Whittington, D., et al. (2005), Water resources management in the Nile Basin: The economic value of cooperation, Water Policy, 7(3), 227-252.

Whittington, D., et al. (2009), The challenge of improving water and sanitation services in less developed countries, Found. Trends in Microecon., 4(6-7), 469-609.

Wichelns, D. (1999), Economic efficiency and irrigation water policy with an example from Egypt, Int. J. Water Resour. Dev., 15(4), 543-560, doi:10.1080/07900629948754.

Wood, A. W., et al. (1997), Assessing climate change implications for water resources planning, Clim. Change, 37(1), 203-228, doi:10.1023/ A:1005380706253.

World Bank (2008), Project Appraisal Document on a Proposed Credit to the Federal Democratic Republic of Ethiopia for a Tana and Beles Integrated Water Resources Development Project, 131 pp., Washington, D. C.

World Commission on Dams (2000), Dams and Development: A New Framework for Decision-Making-The Report of the World Commission on Dams, 356 pp., Earthscan, London.

$\mathrm{Wu}, \mathrm{X}$., and D. Whittington (2006), Incentive compatibility and conflict resolution in international river basins: A case study of the Nile Basin, Water Resour. Res., 42, W02417, doi:10.1029/2005WR004238.

Yao, H., and A. Georgakakos (2003), Nile DST User Manual: River and Reservoir Simulation, 44 pp., Ga. Water Resour. Inst., Ga. Inst. of Technol., Atlanta.

Yeh, W. W.-G. (1985), Reservoir management and operations models: A state-of-the-art review, Water Resour. Res., 21, 1797-1818, doi:10.1029/WR021i012p01797.

M. Jeuland, Sanford School of Public Policy, Duke University, Box 90239, Durham, NC 27708, USA. (marc.jeuland@duke.edu) 